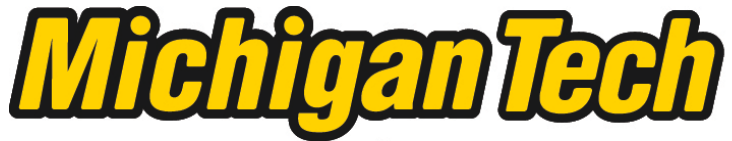 \\ Michigan Technological University Create the Future Digital Commons @ Michigan Tech
}

2014

\section{INVESTIGATION OF AIR JIGGING AND AIR CLASSIFICATION TO RECOVER METALLIC PARTICLES FROM ANALYTICAL SAMPLES}

Hrishikesh Vilas Shinde

Michigan Technological University

Follow this and additional works at: https://digitalcommons.mtu.edu/etds

Part of the Chemical Engineering Commons

Copyright 2014 Hrishikesh Vilas Shinde

Recommended Citation

Shinde, Hrishikesh Vilas, "INVESTIGATION OF AIR JIGGING AND AIR CLASSIFICATION TO RECOVER METALLIC PARTICLES FROM ANALYTICAL SAMPLES", Master's Thesis, Michigan Technological University, 2014.

https://doi.org/10.37099/mtu.dc.etds/874

Follow this and additional works at: https://digitalcommons.mtu.edu/etds

Part of the Chemical Engineering Commons 


\section{INVESTIGATION OF AIR JIGGING AND AIR CLASSIFICATION TO RECOVER METALLIC PARTICLES FROM ANALYTICAL SAMPLES}

By

Hrishikesh Vilas Shinde

A THESIS
Submitted in partial fulfillment of the requirements for the degree of

MASTER OF SCIENCE

In Chemical Engineering

MICHIGAN TECHNOLOGICAL UNIVERSITY

2014

(C) Hrishikesh Vilas Shinde 2014 
This thesis has been approved in partial fulfillment of the requirements for the Degree of MASTER OF SCIENCE in Chemical Engineering.

Department of Chemical Engineering

\author{
Thesis Advisor: $\quad$ Dr. Surendra K Kawatra \\ Committee Member: Dr. Julia King \\ Committee Member: Dr. Gowtham Shankara
}

Department Chair: Dr. Surendra K Kawatra 


\section{Table of Contents}

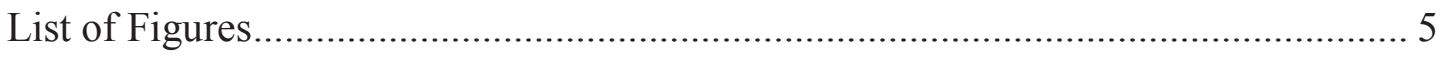

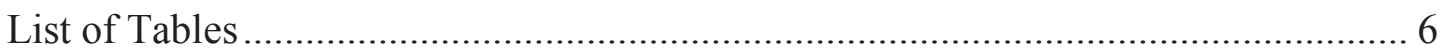

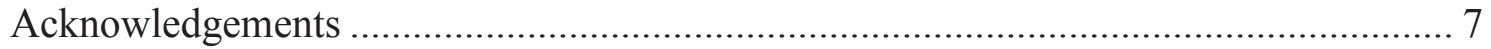

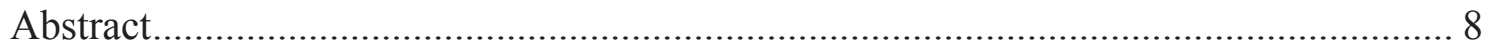

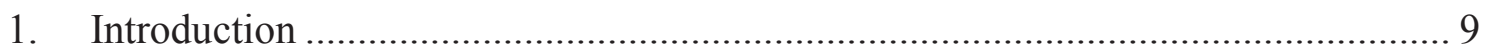

1.1 Current Gold Sampling Scenario ............................................................. 10

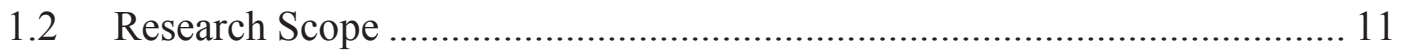

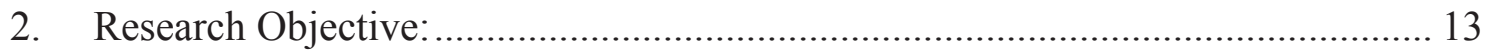

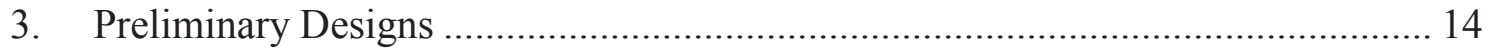

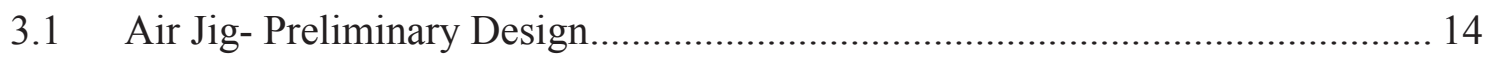

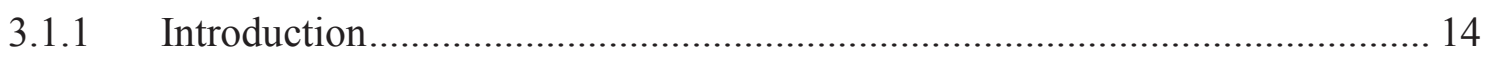

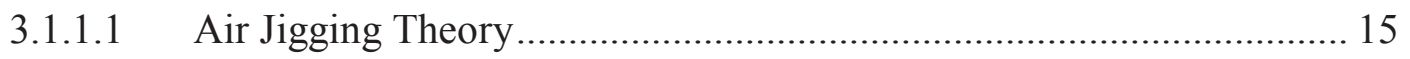

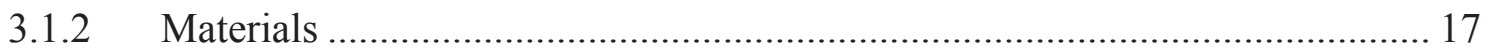

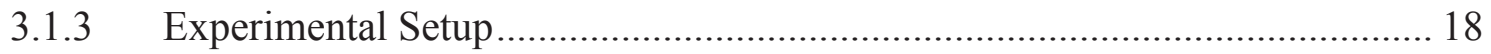

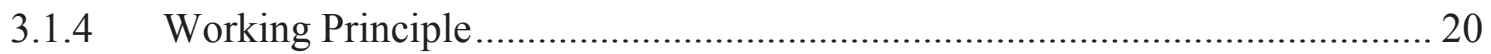

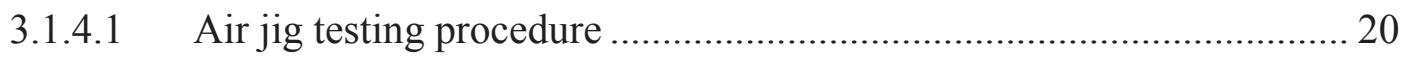

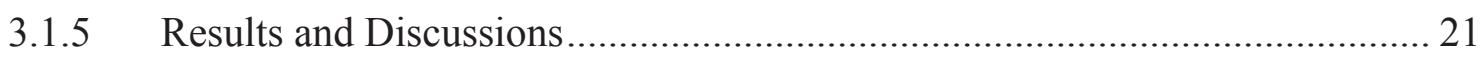

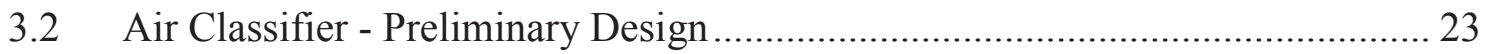

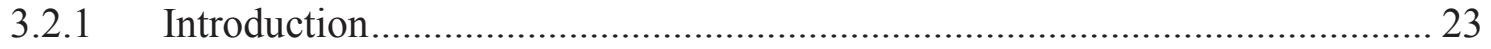

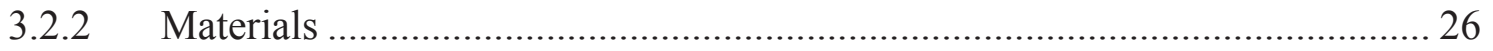

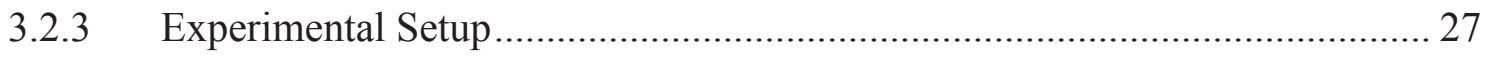

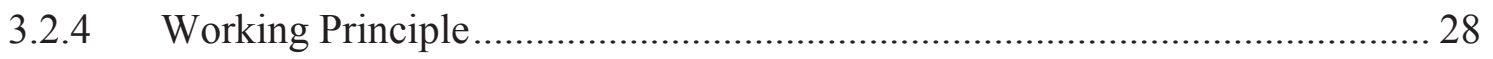

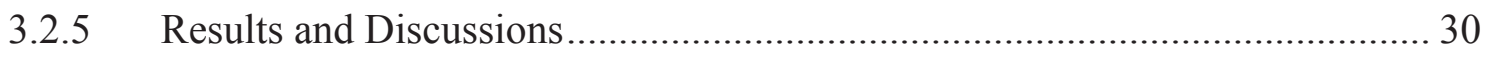

4. Comparison between Preliminary Air Jig and Air Classifier Designs ................... 32

5. Final Design - Air Classifier .......................................................................... 34

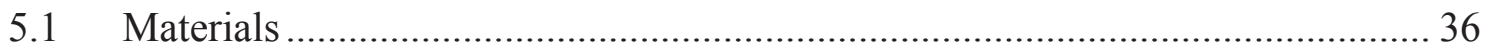

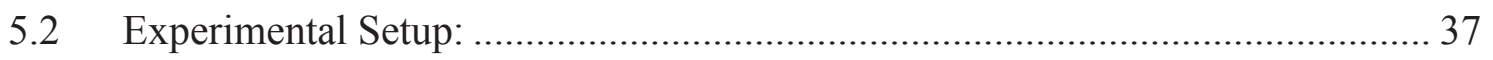

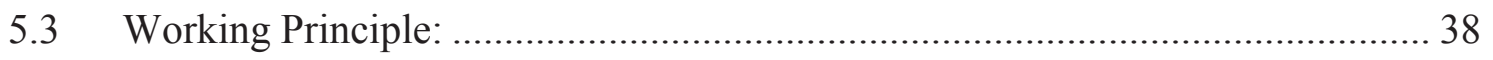

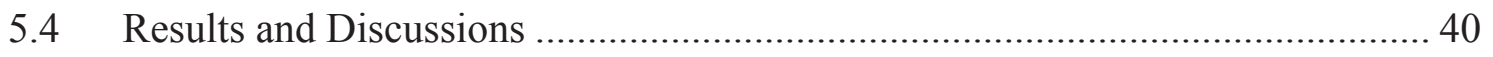

5.4.1 Percent tungsten recovered in the bottom fraction .................................. 40 
5.4.2 Weight collected at the bottom.................................................... 42

5.4.3 Total material recovery from the system .............................................. 44

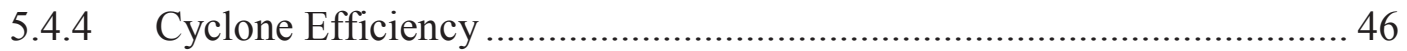

5.4.5 Tungsten and Iron recovery comparison .......................................... 48

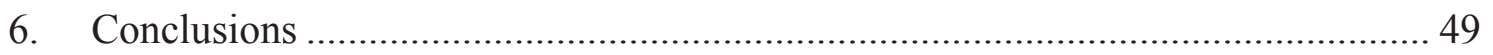

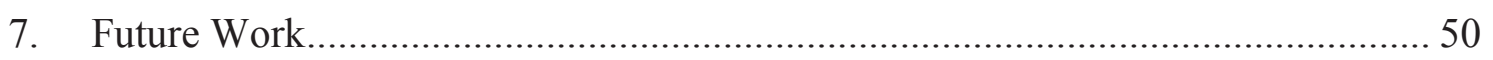






\section{List of Figures}

Figure 1: Current gold sampling scenario ......................................................... 10

Figure 2: Mechanism of Air jigging. Figure adapted from (Gupta and Yang 2006) ..... 15

Figure 3: Size distribution of Newmont samples vs silica crushed at Michigan Tech... 17

Figure 4: Air jigging preliminary design ............................................................... 18

Figure 5: Air jigging laboratory set up and speaker top view ..................................... 19

Figure 6: Force balance on a particle in motion under drag force ............................... 24

Figure 7: Calculated settling velocities of spherical particles of various specific

gravities as a function of particle diameter ................................................................ 25

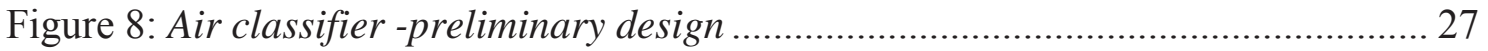

Figure 9: Magnetite-Silica mixture run results .................................................... 30

Figure 10: Cyclone design and cyclone made at Michigan Technological University. . 35

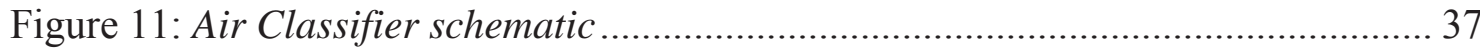

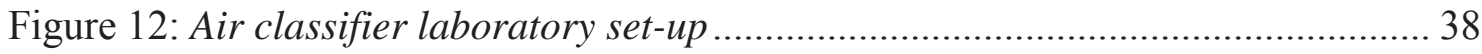

Figure 13: Tungsten recovery into the fire assay concentrate ................................... 40

Figure 14: Weight collected at the bottom of the air classifier (direct fire assay sample)

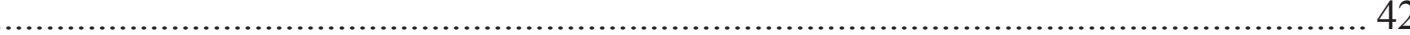

Figure 15: Tungsten recovered vs preconcentrate sample size ................................. 43

Figure 16: Total material recovery (fines fraction plus heavy fraction) ....................... 44

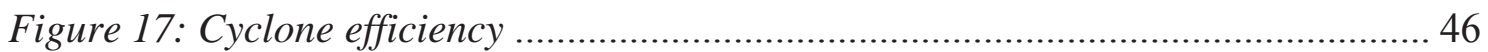

Figure 18: Mineral recovery comparison with change in density. Tungsten and iron

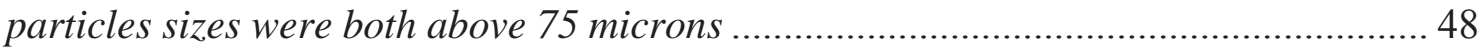




\section{List of Tables}

Table 1: Results from the air jig preliminary design ...............................................21

Table 2: Air classifier (preliminary design) design parameters. .................................27

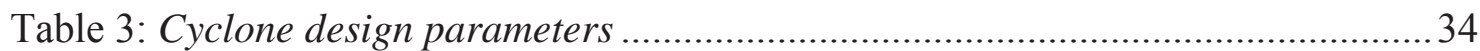




\section{Acknowledgements}

I would like to thank my thesis adviser Dr. S.Komar Kawatra, for his skilled guidance throughout the course of this research.

I would like to thank Joe Halt and Jacob McDonald, graduate students in the department of chemical engineering for conducting preliminary studies on the project; sparkling ideas from men like these make the future of the mineral processing industry. I appreciate the trust that they showed in me while letting me conduct further investigations on their startup research project. I would like to specifically thank Joe Halt for his time in reading my work and providing valuable feedback. He has been of great help to me during my master's research.

I would like to thank Howard Haselhuhn for his exemplary display of mentorship skill towards helping me in every way possible while my time at Michigan Tech. I would like to take this opportunity to thank him for every single time that he has vouched for me in our industry meetings.

I would like to acknowledge Advanced Sustainable Iron and Steel Making Center (ASISC) and Newmont Mining Corporation for their project support.

Last but not the least, I would like to thank my family for their constant support and encouragement. 


\title{
Investigation of Air Jigging and Air Classification to Recover Metallic Particles from Analytical Samples
}

\begin{abstract}
Analyzing "nuggety" gold samples commonly produces erratic fire assay results, due to random inclusion or exclusion of coarse gold in analytical samples. Preconcentrating gold samples might allow the nuggets to be concentrated and fire assayed separately. In this investigation synthetic gold samples were made using similar density tungsten powder and silica, and were preconcentrated using two approaches: an air jig and an air classifier. Current analytical gold sampling method is time and labor intensive and our aim is to design a set-up for rapid testing. It was observed that the preliminary air classifier design showed more promise than the air jig in terms of control over mineral recovery and preconcentrating bulk ore sub-samples. Hence the air classifier was modified with the goal of producing 10-30 grams samples aiming to capture all of the high density metallic particles, tungsten in this case. Effects of air velocity and feed rate on the recovery of tungsten from synthetic tungsten-silica mixtures were studied. The air classifier achieved optimal high density metal recovery of $97.7 \%$ at an air velocity of $0.72 \mathrm{~m} / \mathrm{s}$ and feed rate of $160 \mathrm{~g} / \mathrm{min}$. Effects of density on classification were investigated by using iron as the dense metal instead of tungsten and the recovery was seen to drop from $96.13 \%$ to $20.82 \%$. Preliminary investigations suggest that preconcentration of gold samples is feasible using the laboratory designed air classifier.
\end{abstract}




\section{Introduction}

Determining the gold content of low-grade ores $(<5 \mathrm{~g} / \mathrm{t})$ is a labor- and time- intensive process. Furthermore, the presence of the "Nugget Effect" (where the bulk of the gold content is found in a few sporadic nuggets) can cause erratic fire assay results. When analytical samples are prepared, small amounts (10 grams, Clifton et al. 1969) of samples are randomly chosen to be analyzed by fire assay or by atomic adsorption spectroscopy to estimate the gold content. This sample is assumed to be a representative of the analytical sample but the presence or absence of gold nugget in this randomly chosen sample from the analytical sample cannot be assured. The inclusion or exclusion of these nuggets in a particular analytical sample can have an effect of over-estimating or underestimating the total gold content respectively. Hence a method to preconcentrate all the gold particles and nuggets from a bulk sample into a sample small enough to be analyzed directly by fire-assay / atomic adsorption spectroscopy needs to be formulated.

Current approach towards gold sampling is screening. This is a tedious time-and-labor intensive approach. Can this approach be addressed by developing an alternative rapid testing approach that takes advantage of high density gold particles in the gold ore?

The potential of a Knelson concentrator was recently investigated as a means to preconcentrate bulk gold samples. Typically operated on a wet basis, it was suggested to convert a Knelson concentrator to a dry basis by using air instead of water (Greenwood 2013). Tungsten recovery was seen to range between $70-80 \%$ for particles in a size range of -300 to +38 microns at an air pressure of 2 PSI, but the tungsten grade was very poor. A wind tunnel designed to classify granular material particles of approximately similar density with varying particle size has been patented as granular material separating device (Vickery 1991); this device consists of a scattering assembly which facilitates effective dispersion of the granular feed material prior to classification. The granular material separating device can be more effectively used as a gold separation tool rather than an analytical gold sampling tool. Gold pans with water delivery cups were designed and patented to separate gold particles from black sand (Krenzler 1999). 


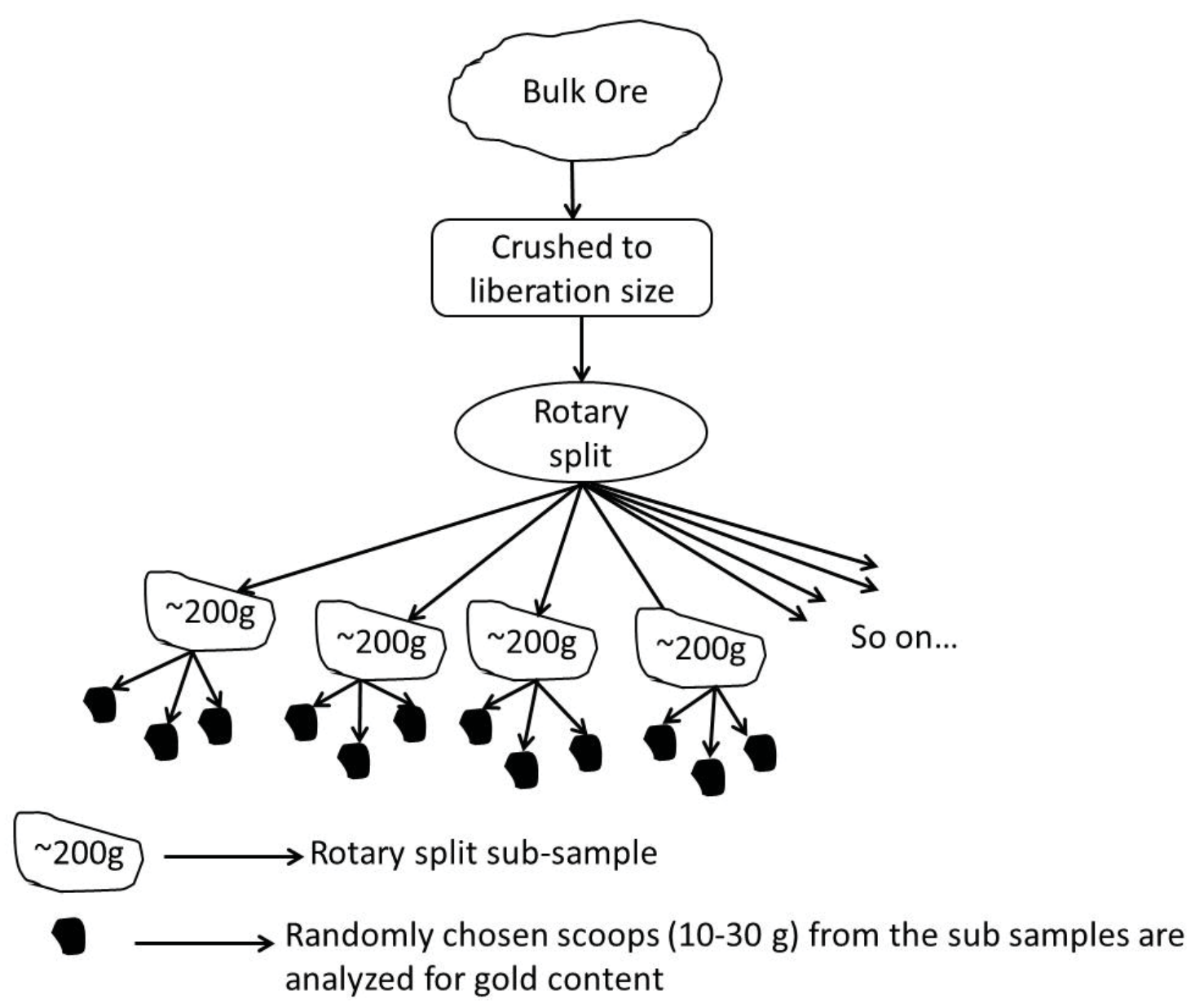

Figure 1: Current gold sampling scenario

\subsection{Current Gold Sampling Scenario}

The causes and nature of nugget effect have been studied (Carrasco 2010). Gold sampling leads to erratic results due non-uniform distribution and nuggety nature of gold ore. The current gold sampling scenario is demonstrated in Figure 1.

To determine the potential of gold mining on a desired site, bulk ore samples are crushed until the mineral liberation size. The crushed sample is rotary split to sub-samples weighing approximately 200 grams and from these samples, random scoops weighting between 10-30 grams are selected and analyzed for their gold content by using techniques like atomic adsorption spectroscopy or fire assaying. The underlying assumption is that the random scoop is a representative of the rotary split sub- sample. In case of nuggety gold sample the inclusion or exclusion of the gold nugget from the scoop (10-30 grams) will lead to erratic spectroscopy or fire assay results due to non-uniform gold distribution. 
Hence there is a need to develop an approach to reduce the erratic nature of sampling and to minimize time-and-labor requirements.

\subsection{Research Scope}

In this thesis, we investigate the potential for air jigging and air classifier to be applied to preconcentrate gold particles in analytical gold sampling. Synthetic gold ore made from tungsten and silica was used to mimic actual gold ore in all the experiments. A dry basis was chosen for rapid separation and sample analysis.

Air classifiers are widely used in a variety of applications mainly including de-dusting of fines, controlling particle size distribution and removing impurities and contaminants from valuable products. Specific applications include (Everett and Peirce 1990, Muscolino 2010):

- Removal of fine dust particles from coarse aggregate products.

- Controlling the size distribution of dry-milled powders such as limestone, silica, feldspar, zirconia, alumina, and cementitious materials.

- Recovering valuable metallics from mineral processing slags.

- Segregating valuable material from municipal solid waste to be used as Refuse Derived Fuel.

Similarly, jigging is also used in a variety of applications:

- Separation of mineral contaminants from coal using an air jig (Oder and Weinstein 2008).

- Recovering ferroalloys [Ferrochrome (FeCr), Ferromanganese (FeMn), and Ferrovanadium $(\mathrm{FeV})]$ from slag to recover metal value.

Classifier designs vary based on the desired separation to be carried out, but the separation is governed by particle behavior in the imposed air flow. Our design is a simple straight tube air classifier which classifies particles based on their terminal settling velocities. 
Similarly, jigs may operate on either wet or dry basis depending on the jigging fluid. Our jig design incorporates air as the jigging fluid and the speaker generates pulsations of air through the particle bed and separates particles based on their density and size. 


\section{Research Objective:}

Our research objectives were as follows:

- We planned to construct and test an air jig and air classifier to compare their abilities to separate a high density gold analogue (tungsten) from 200-300 grams of silica.

- Determine most effective approach amongst the air jig and air classifier and improve its design to maximize high density metal capture into a sample smaller than 30 grams.

- Rationale for selecting tungsten for experimental trials: tungsten was chosen to mimic gold because of its closeness in density with gold. Gold will behave in a similar fashion as tungsten, and hence, if the testing procedure is feasible for separating tungsten from a tungsten-silica mixture, it can be applied to separate gold from gold ore. 


\section{Preliminary Designs}

Two designs were initially proposed, an air jig and an air classifier. Each of them are described separately in this section.

\subsection{Air Jig- Preliminary Design}

\subsubsection{Introduction}

Jigging is a well-known method of gravity concentration. Jigging separates minerals of different densities based on their behavior under gravity and the resistance to motion

offered by a viscous fluid, such as air or water. Effective separation can be ensured if there is a significant density difference between the mineral and the gangue. The ease of separating a heavy mineral from a light mineral from a mineral mixture by jigging can be predicted using a ratio known as "concentration criterion" C.C., (Wills 1985):

$$
\text { C.C. }=\frac{D_{h}-D_{l}}{D_{l}-D_{f}}
$$

\section{Equation 1}

Where, $D_{h}$ is the density of heavy mineral, $D_{l}$ is the density of light mineral/gangue, and $D_{f}$ is the density of the fluid medium. If the concentration criterion is greater than 2.5 gravity separations are relatively easy and are highly efficient.

\section{Example Calculation:}

Concentration criterion calculations for Tungsten-Silica mixtures with air as the fluid medium are as shown below.

Density of heavy mineral (tungsten), $D_{h}=19.3 \mathrm{~g} / \mathrm{cm}^{3}$

Density of light mineral (silica), $D_{l}=2.65 \mathrm{~g} / \mathrm{cm}^{3}$

Density of fluid medium (air), $D_{f}=0 \mathrm{~g} / \mathrm{cm}^{3}$ (approximated to be zero)

On substituting for densities in the C.C. Equation, we have:

$$
\text { C.C. }=\frac{19.3-2.95}{2.65-0}=6.28
$$


The concentration criterion of 6.28 for jigging tungsten from silica indicates a very easy separation. Jigging units can achieve a good recovery down to 150 microns and acceptable recoveries down to 75 microns (Wills 1985). Our project describes gold nuggets to be in the size range of 75 microns and above, which implies acceptable recoveries based on concentration criterion. Bulk samples can be ground and sized to the desired feed size range for jigging.

\subsubsection{Air Jigging Theory}

In a jig, the separation of minerals of different densities is accomplished in a bed which is fluidized by a pulsating current of air or water so as to produce stratification. Jigging periodically expands and contracts the packed bed of materials being treated and controls the dilation so that the heavier, smaller particles rise up through the gaps of the bed and the larger high density particles fall down to the bottom of the bed. The pulsed air lifts the bed as a mass, then as velocity decreases the bed tends to expand; fine particles pass upwards through the gaps in the bed and coarse particles fall to the bottom.

Mechanisms of air jigging can be explained based on the following steps shown in Figure 2:

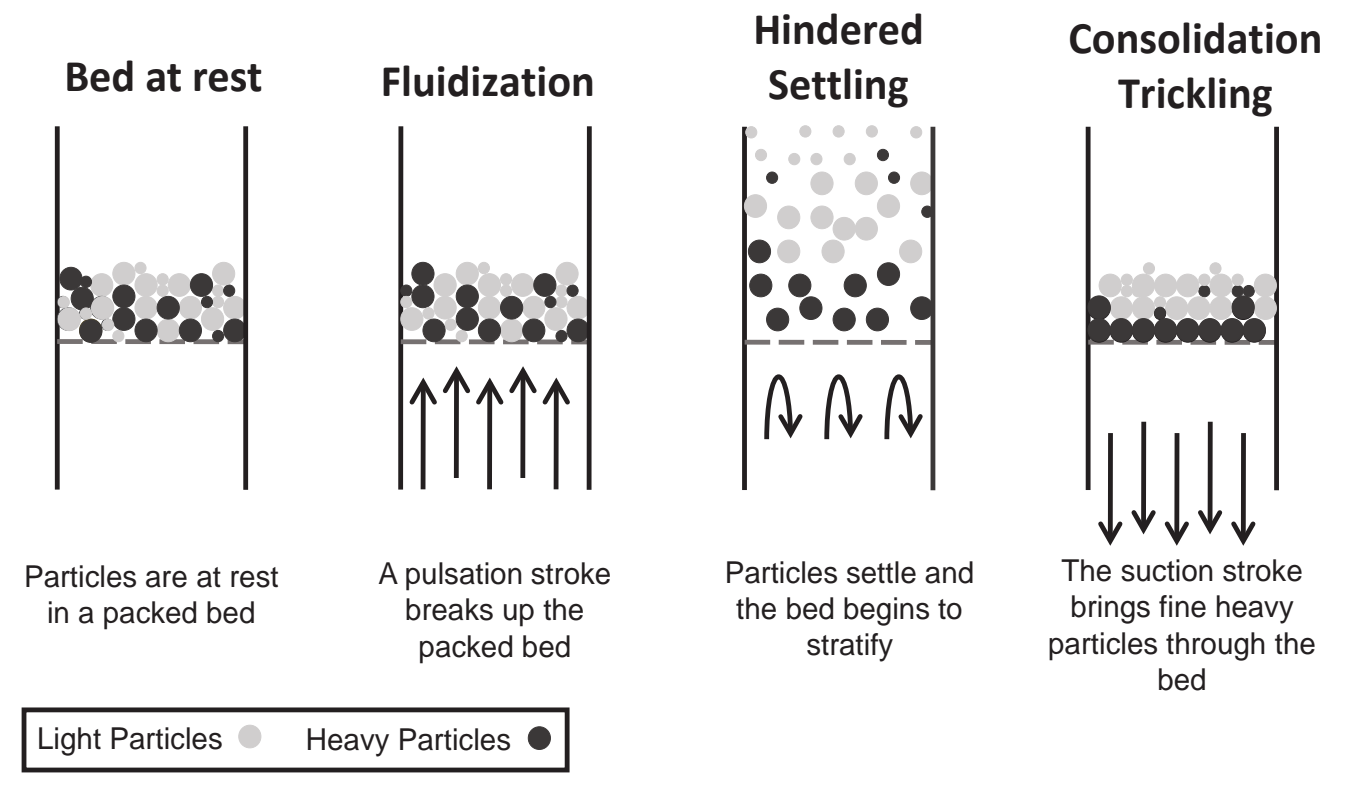

Figure 2: Mechanism of Air jigging. Figure adapted from (Gupta and Yang 2006) 
Each step from the above figure can be explained as follows:

- Bed at rest: The particle bed is at rest on top of the screen.

- Fluidization: The particle bed is given a pulsed motion by pulsation of compressed air. Differential acceleration separates based upon density alone. This stroke can be provided by means of a plunger; in our case we used an amplifier to provide the pulsation.

- Hindered Settling: As the pulsation stroke continues and goes into the suction stroke, hindered settling is the key mechanism of separation. At this point drag forces start becoming important and the particles separate based on density and size.

- Consolidation Trickling: Finally, the bed compacts during the suction stroke. The fine dense particles are pulled through the dense coarse particles and into the dense particle concentrate. This is called consolidation trickling, and is dependent on particle size. 


\subsubsection{Materials}

Synthetic ore was prepared by mixing silica and tungsten powder to mimic the composition of gold ore. Tungsten was chosen to mimic gold due to closeness in densities (tungsten $19.25 \mathrm{~g} / \mathrm{cm}^{3}$ and gold $19.3 \mathrm{~g} / \mathrm{cm}^{3}$ ) and will therefore behave similar to gold.

Tungsten Powder: Tungsten alloy shavings were ground to tungsten powder and sized to a $-100+270$ mesh. The density of tungsten was determined to be approximately16.3 $\mathrm{g} / \mathrm{cm}^{3}$. Tungsten was sized in this manner because to represent gold distribution in Newmont gold samples.

Silica: Ottawa sand was procured from US Silica. Bulk silica material was sized into the following size fractions (Tyler mesh) and these size fractions were mixed in proportions representative to Newmont gold samples as 48x65, 65x100, 100x150, 150x250, 250x325, $325 \times 500$, and -500 (Figure 3). Silica density was determined to be $2.64 \mathrm{~g} / \mathrm{cm}^{3}$.

Density was measured using specific gravity bottles.

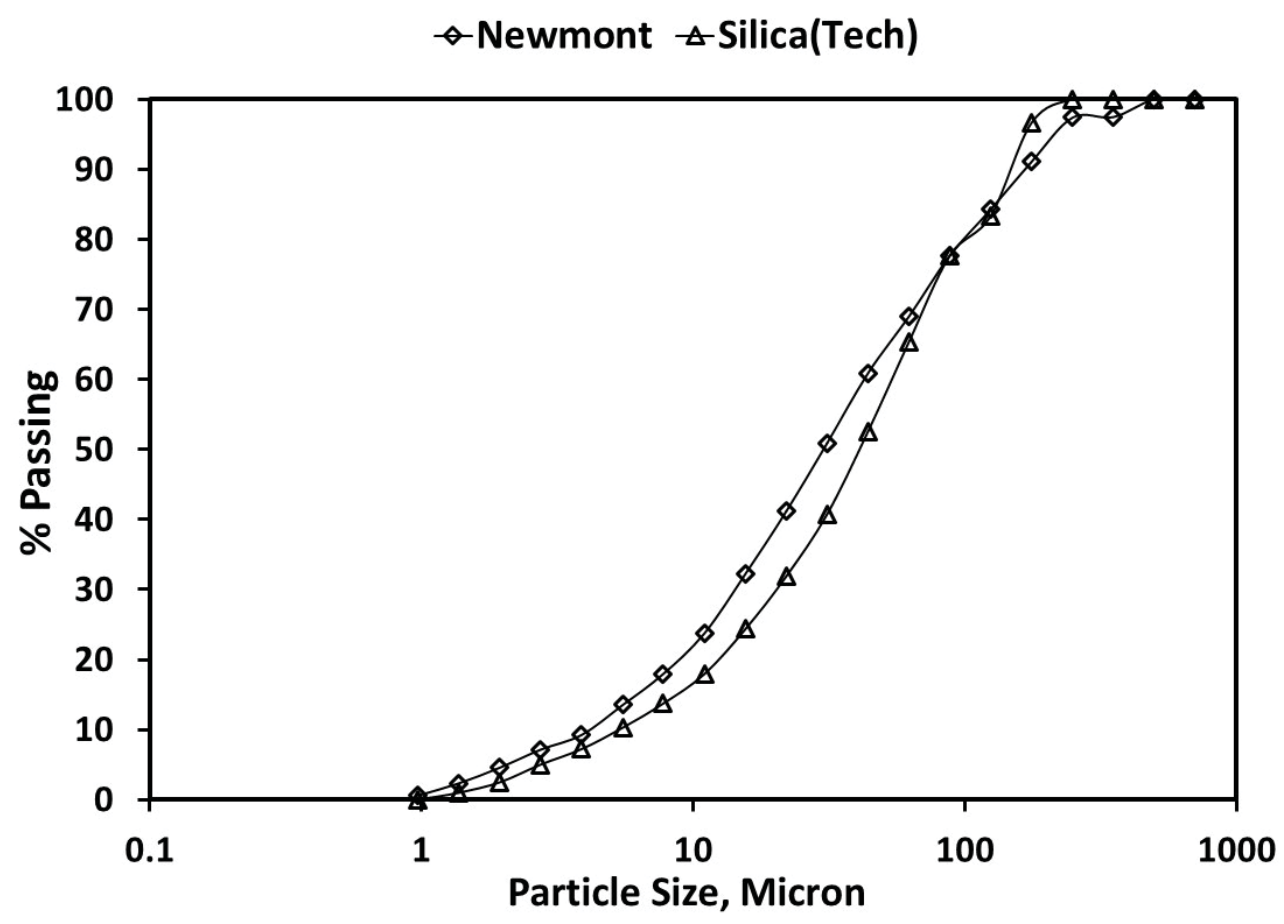

Figure 3: Size distribution of Newmont samples vs silica crushed at Michigan Tech. 


\subsubsection{Experimental Setup}

An air jigging unit was designed shown in Figure 4 and its laboratory scale experimental setup is shown in Figure 5.

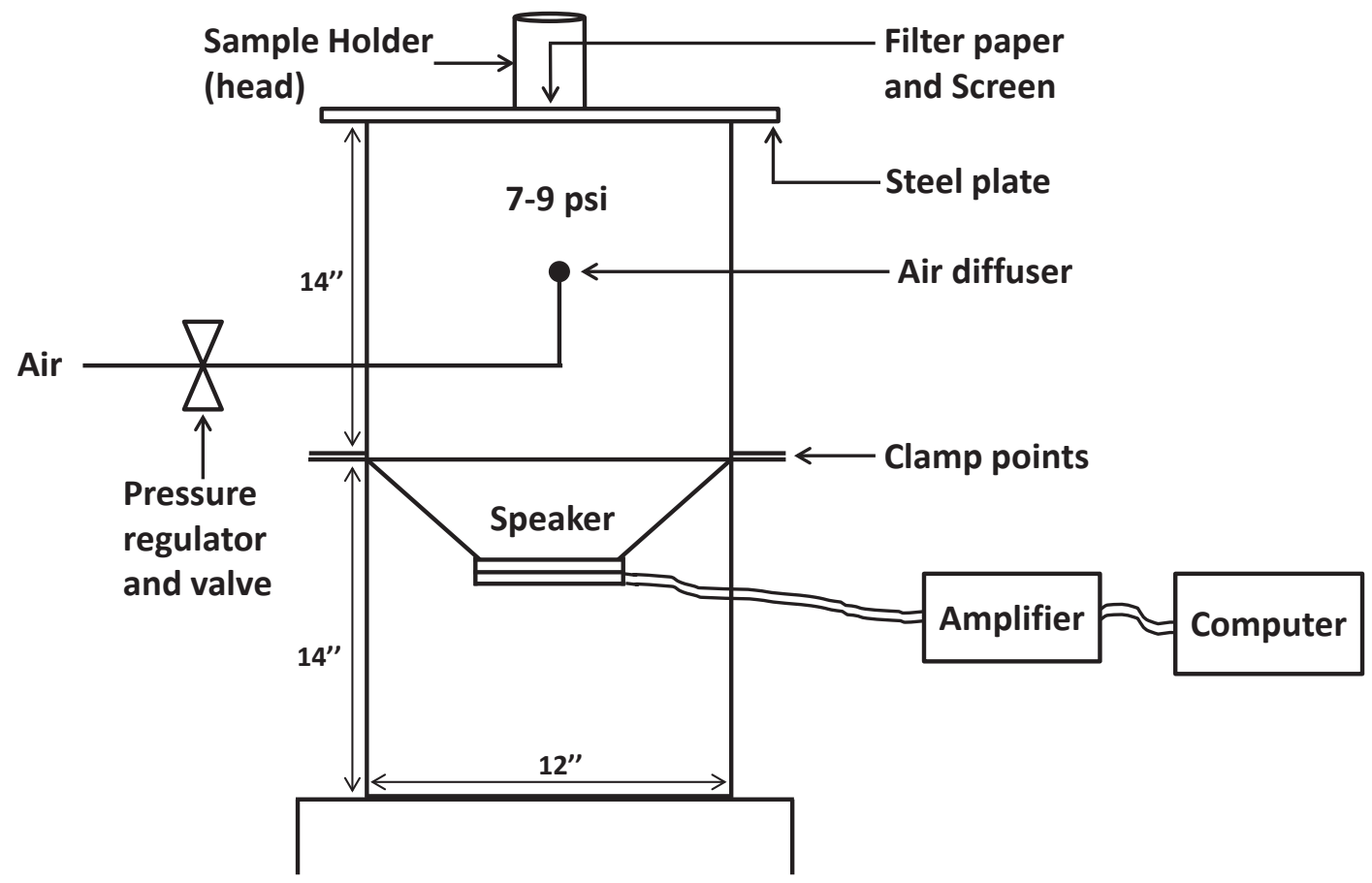

Figure 4: Air jigging preliminary design

The Air Jig has the following important parts:

- Sample holder (head): Our design consisted of an open vessel which acted as a sample holder, with a relatively coarse screen (openings larger than the size of the coarsest particle) at the bottom.

- A filter paper below the screen ensures that the coarse material was retained on the screen. The screen holds the material in place and disperses air flow allowing good bed fluidization.

- The preconcentrate is collected from the bottom of the sample holder.

- Pressure Regulator: A side port allowed supply of constant pressure air to be introduced; this pressure was typically maintained between 7-9 PSI.

- Air Diffuser: Helped in fluidizing the incoming air. 
- Speaker (Frequency Generator): Bed pulsation was provided by a 12 inch 1440 Watt subwoofer (speaker) powered by a computer and signal amplifier. The speaker frequency was varied between $25-125 \mathrm{~Hz}$.
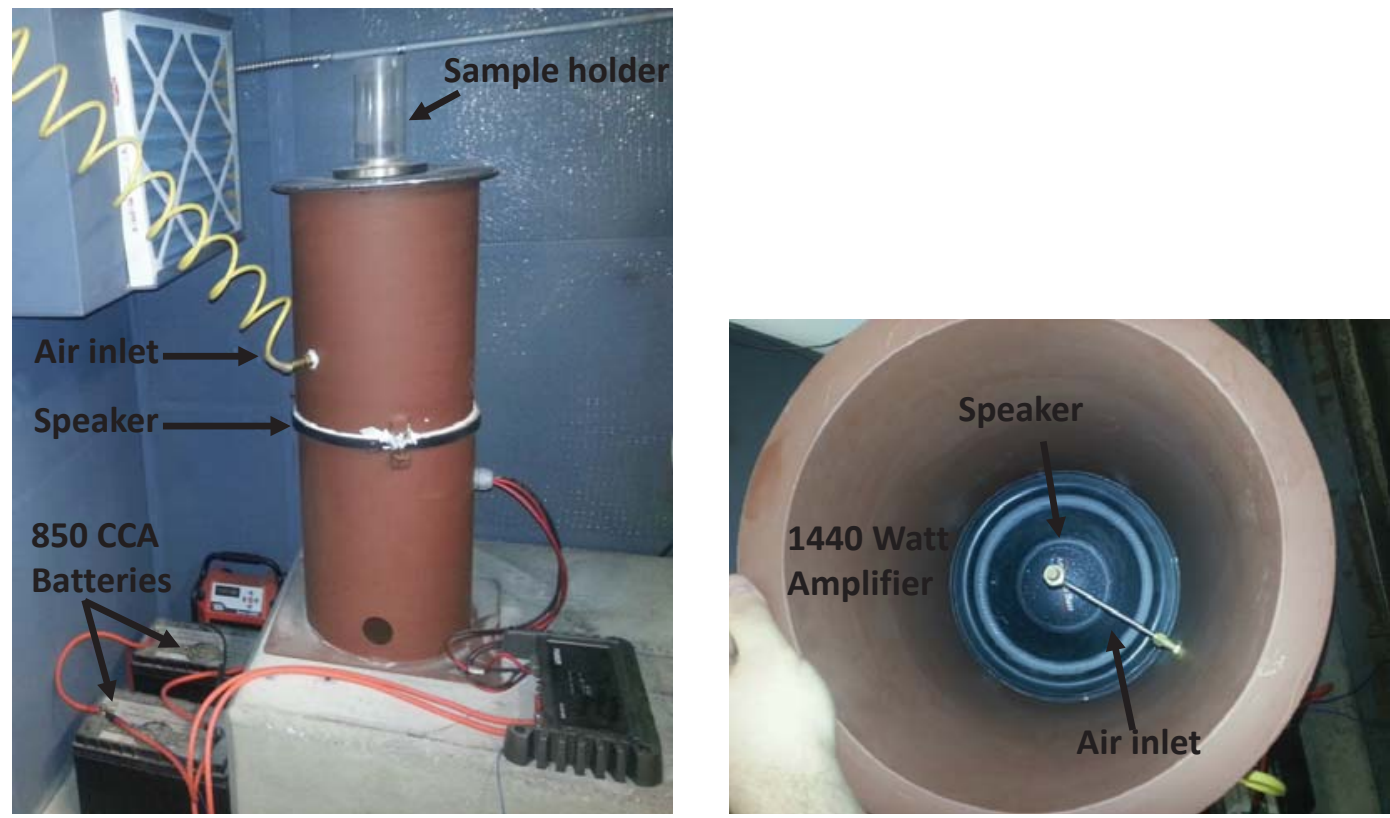

Figure 5: Air jigging laboratory set up and speaker top view 


\subsubsection{Working Principle}

Fluidization of fine particles cannot be easily achieved by airflow alone. Some type of agitation must be introduced to disrupt any channeling that may occur. When a pulse of air is forced in, it will rise up through the screen and fluidize the bed of particles allowing the coarser, higher-density material to descend through the other particles. Head space at the top of the vessel will allow the bed to expand as fluidization increases the bed volume. When the bed expands, dense and light particles are suspended in the sample holder and dense particles settle down because their density is much greater than that of the bulk density of the bed. When fluidization ends, heavy particles settle below light particles in the bed; they are then separated by carefully sliding the sample holder (Figure 4) across, to separate fines and the bottom of the bed is collected and weighed. Due to the sample holder design this jigging was a batch process and not operator friendly. Combining frequencies increases the sharpness of the pulse, causing an increase in fluidization. The pulsation cycle could repeat for 25-125 pulsations per minute allowing ample opportunities for the metallics to migrate to the bottom of the suspended bed and to be removed.

\subsubsection{Air jig testing procedure}

The procedure used for testing of air jig was as follows (Tungsten-Silica mixtures):

- Known mass of silica (250-500 grams) was prepared and placed into the sample holder.

- Air flow was increased, typically to 7 PSI until the silica surface began to "bubble". When a pulse of air was forced in, it rises up through the screen and fluidizes the bed of particles allowing the coarser, higher-density material to descend through the other particles.

- Signal amplifier was turned on.

- Silica bed was allowed to fluidize and air flow was adjusted as required and recorded. When the bed expands, dense and light particles are suspended in the sample holder and dense particles settle down because their density is much greater than that of the bulk density of the bed. 
- Known mass of tungsten alloy (2-6 grams) was added to the fluidized bed and the fluidization times are timed.

- At a predetermined time signal amplifier and air supply are turned off, sample is removed and metal (tungsten) recovery was estimated by panning the concentrate.

\subsubsection{Results and Discussions}

Table 1: Results from the air jig preliminary design

\begin{tabular}{|c|c|c|c|c|c|c|c|c|}
\hline $\begin{array}{c}\text { Run } \\
\text { No. }\end{array}$ & $\begin{array}{c}\text { Freq. } \\
\text { (Hz) }\end{array}$ & $\begin{array}{c}\text { Time } \\
\text { (min) }\end{array}$ & $\begin{array}{c}\text { Silica } \\
\text { (g) }\end{array}$ & $\begin{array}{c}\text { Tungsten } \\
\text { (g) }\end{array}$ & $\begin{array}{c}\text { Concentrate } \\
\text { (g) }\end{array}$ & $\begin{array}{c}\text { Metal } \\
\text { in } \\
\text { Conc. } \\
\text { (g) }\end{array}$ & $\begin{array}{c}\text { \% Mass } \\
\text { Reduction }\end{array}$ & $\begin{array}{c}\text { \% Metal } \\
\text { Recovery }\end{array}$ \\
\hline 1 & $45 / 60 / 80$ & 2 & 265.6 & 2.99 & 114.6 & 1.71 & 57.33 & 57.21 \\
2 & $45 / 60 / 80$ & 2 & 259.9 & 3.19 & 95.6 & 2.53 & 63.66 & 79.35 \\
3 & $45 / 60 / 80$ & 2 & 502.8 & 3.99 & 122.5 & 1.18 & 75.83 & 29.58 \\
4 & $45 / 60 / 80$ & 2 & 500.4 & 3.97 & 130 & 3.07 & 74.23 & 77.28 \\
5 & $45 / 60 / 80$ & 5 & 500.2 & 4.01 & 123.8 & 1.40 & 75.45 & 34.84 \\
6 & $45 / 60$ & 2 & 302.8 & 5.78 & 126.9 & 5.16 & 58.88 & 89.25 \\
7 & $45 / 60$ & 2 & 303 & 2.49 & 128 & 1.69 & 58.10 & 67.87 \\
8 & $45 / 60$ & 2 & 303.4 & 2.75 & 129.5 & 2.42 & 57.70 & 87.97 \\
9 & $45 / 60$ & 2 & 304.5 & 2.92 & 124.1 & 2.04 & 59.63 & 69.98 \\
10 & $45 / 60$ & 5 & 300 & 2.32 & 127.4 & 1.33 & 57.86 & 57.41 \\
\hline
\end{tabular}

Tungsten-silica mixture samples were introduced into the fluidization bed, frequency and fluidization time were varied and the observations are as shown in Table 1.

$$
\% \text { Mass Reduction }=\left(1-\frac{\text { Wt. of Concentrate }}{\text { Wt of Silica fed }+ \text { Wt. of Tungsten fed }}\right) * 100
$$

Equation 2

The air jig was fluidized using two different combinations of multiple frequencies. Multiple frequencies combinations were achieved by overlapping frequencies on a computer program. Fluidization was carried out for 2 and 5 minutes. Percentage mass reduction is important due to the desired size of analytical samples (15-30 grams) and hence it is essential to have a high \% mass reduction and high \% metal recovery for the same set of parameters. The air pressure for all the runs was maintained constant at $7 \mathrm{psi}$. 
Frequency combinations of $45 / 60 / 80 \mathrm{~Hz}$ were investigated in order to optimize recovery, but it was observed that when the bed was fluidized for 2 minutes, there was a wide range of inconsistency in the metal recovery, 57.21 and $79.35 \%$ for runs 1 and 2 respectively. When the amount of silica in the feed was increased for the same combinations of frequency (runs 3 and 4), it was observed that the metal recovery showed a wider range of inconsistency with 29.58 and $77.28 \%$ recovery for runs 3 and 4 respectively. When fluidizing time was increased to 5 minutes (run 5), the recovery decreased to $34.84 \%$, indicating that the problem was not insufficient time.

For a frequency combination of 45/60, and fluidizing time of 2 minutes, it was observed that the $\%$ metal recovery was still inconsistent. Percentage metal recovery for runs 6,7 , 8 and 9 (replicate runs) varied from 67.87 to $89.25 \%$, showing an increase in metal recovery as compared to the prior runs. When the fluidization time was increased to 5 minutes for run 10 , the $\%$ metal recovery was seen to fall down to $57.41 \%$. Reasons for this drop in recovery are unknown.

A consistency in the concentrate mass was observed due fixed size of the sample holder, as the sample holder can hold approximately 120 grams. However, the metal recovery results showed inconsistency when tested for repeatability despite of similar percent mass reduction.

The objective of the preliminary design was to generate samples the size of analytical samples with maximum mineral recovery. Preliminary testing using the designed air jig were not promising due to poor and inconsistent recovery, and, insufficient mass reduction of the bulk samples so a second approach was evaluated, air classification. 


\subsection{Air Classifier - Preliminary Design}

\subsubsection{Introduction}

Classification is a method of separating mixtures of minerals into two or more products on the basis of the velocity with which the particles fall through a fluid medium (Wills 1985). A classifier sizes particles according to their settling velocities. Particle settling velocity is affected by the following factors:

- Density affects the particle mass and therefore its settling velocity. Particle behavior in air can be discussed based on the aerodynamic diameter.

- Particle shape affects the particle behavior as particles deviate from spherical shape. Irregular surface area introduces a variable drag force on a particle in the air stream, which may cause difficulty in separation. Most calculations assume the particle shape to be spherical as it is difficult to determine shape factors of non-spherical particles (Wilson and Huang 1979).

Aerodynamic diameter is defined as the diameter of a sphere with unit density that has aerodynamic behavior identical to that of the particle in question (EPA 2011). Particles having the same aerodynamic diameter may have different dimensions and shapes. If the particle diameter $\left(\mathrm{d}_{\text {particle }}\right)$ and density of a powder $\left(\rho_{\text {particle }}\right)$ are known, the aerodynamic diameter $\left(\mathrm{d}_{\mathrm{aero}}\right.$ ) can be estimated based on Equation 3 (Zelenyuka et al. 2005).

$$
d_{\text {aero }}=d_{\text {particle }} \sqrt{\frac{\rho_{\text {particle }}}{\rho_{\text {aero }}}}
$$

Equation 3

Where $\rho_{\text {aero }}=1000 \mathrm{~kg} / \mathrm{m}^{3}$

For example, a 74 micron particle with density $2000 \mathrm{~kg} / \mathrm{m}^{3}$ will behave in the same manner as a 53 micron particle with a density $4000 \mathrm{~kg} / \mathrm{m}^{3}$; both have an aerodynamic diameter of 105 micron. 
In an air classifier, particles of varying size, shape and density are acted upon by fluid drag, gravity and buoyancy forces (Figure 6). Buoyancy is often neglected because the density of solid particles is much greater than the density of air; hence, the buoyant force is negligible. Under free fall, particles accelerate continuously due to their weight, but the influence of a fluid drag force resists their downward motion. When particles are fed to the classifier, if the drag force exceeds the weight, particles get swept out of the top of the classifier. Conversely, when the weight exceeds the drag force, particles travel downwards and are collected at the bottom.

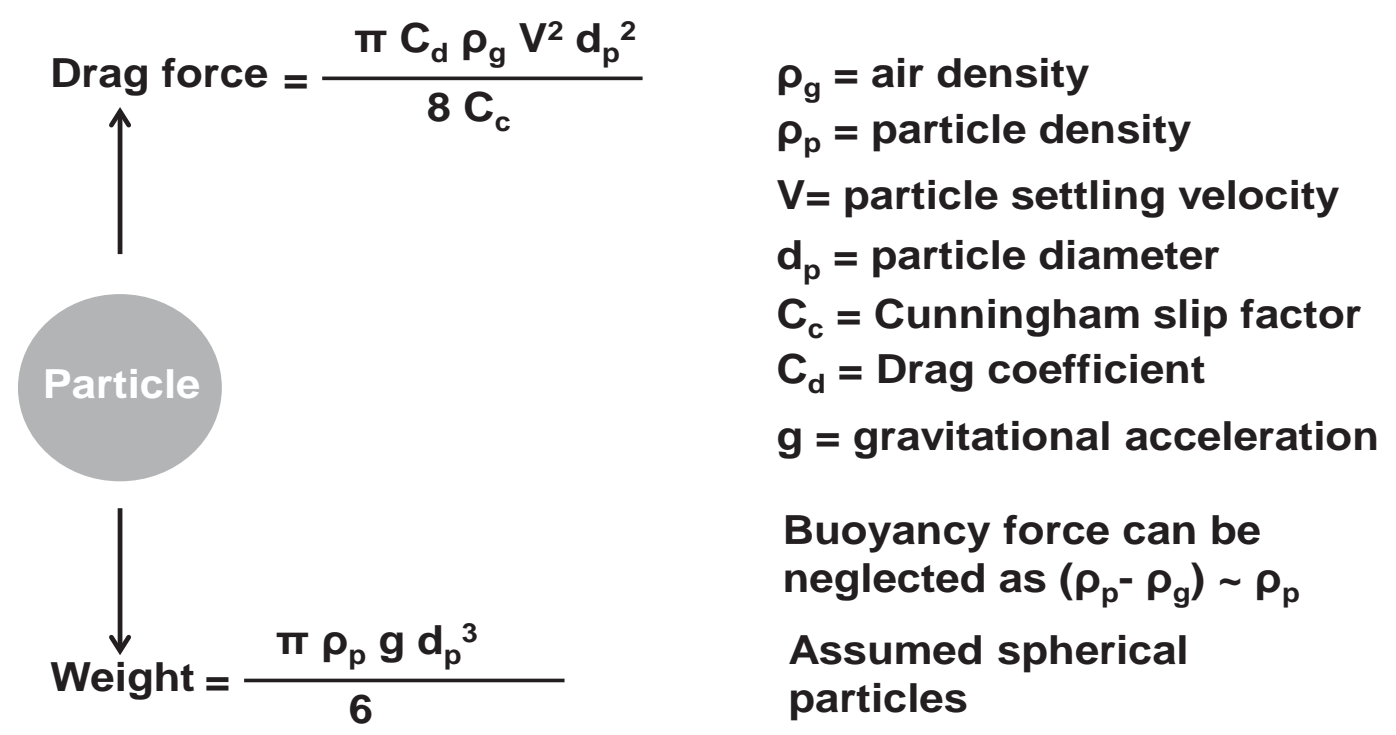

Figure 6: Force balance on a particle in motion under drag force

On equating drag force and particle weight, particle settling velocity is written as (Baron 2001):

$$
v=\left(\frac{4 \rho_{p} g d_{p} C_{c}}{3 C_{d} \rho_{g}}\right)^{1 / 2}
$$

Equation 4

This equation can be used to predict the necessary air velocity required for separation. For particle diameters 0.5 to 150 microns, the terminal settling velocity is determined by substituting values for $d_{p}$ and $C_{d}$. Drag coefficient $C_{d}$, depends on the Reynolds 
number. Corresponding settling velocities are plotted against particle diameters and the air velocity required for separation can be predicted. Settling velocities for gold (density $19.3 \mathrm{~g} / \mathrm{cm}^{3}$ ), silica (density $2.65 \mathrm{~g} / \mathrm{cm}^{3}$ ) and iron (density $6.73 \mathrm{~g} / \mathrm{cm}^{3}$ ) were estimated and plotted as shown in Figure 7.



Figure 7: Calculated settling velocities of spherical particles of various specific gravities as a function of particle diameter

For example, in a classifier with air velocity $1 \mathrm{~m} / \mathrm{s}$, particles with settling velocity above $1 \mathrm{~m} / \mathrm{s}$ are collected at the bottom and that below $1 \mathrm{~m} / \mathrm{s}$ are swept out from the top of the separation column.

From Figure 7, it can be seen that, for an air velocity of $1 \mathrm{~m} / \mathrm{s}$, gold-silica separation may be easier for particles of larger size. It can also be observed that as particles diameter decreases, the particle settling velocity decreases and hence separating particles with small diameter becomes difficult for a given air flow. For two particles with similar diameters but with different densities, the particle with higher density will have higher 
settling velocity and will settle faster at the bottom as compared to the low density particle.

In order to optimize the tungsten recovery and ensure that all the tungsten/gold particles are collected at the bottom of the separation column, air velocity can be varied to achieve an optimum separation.

\subsubsection{Materials}

Feasibility of the preliminary air classifier design to preconcentrate bulk sub-samples was first studied with unmixed samples of silica and tungsten. Later on, Magnetite-Silica mixtures were also tested.

Silica: Ottawa sand was purchased from US Silica. Silica was crushed to achieve a size distribution of $80 \%$ passing 140 microns (Figure 3). Density of silica was determined to be $2.65 \mathrm{~g} / \mathrm{cm}^{3}$.

Magnetite powder: magnetite powder was produced from a coarse magnetite particles. The coarse sample was crushed and sieved into the following size fractions: $14 \times 3,30 \times 48$, $48 \times 100,100 \times 200$ and $200 \times 270$. The density of magnetite powder was determined to be $5.15 \mathrm{~g} / \mathrm{cm}^{3}$.

Tungsten powder: tungsten alloy shavings were ground to tungsten powder and sized to a $-100+270$ mesh. The density of tungsten was determined to be approximately 16.3 $\mathrm{g} / \mathrm{cm}^{3}$.

Density measurements were done by using specific gravity bottle method. 


\subsubsection{Experimental Setup}

A preliminary air classifier design was proposed as shown below in Figure 8:

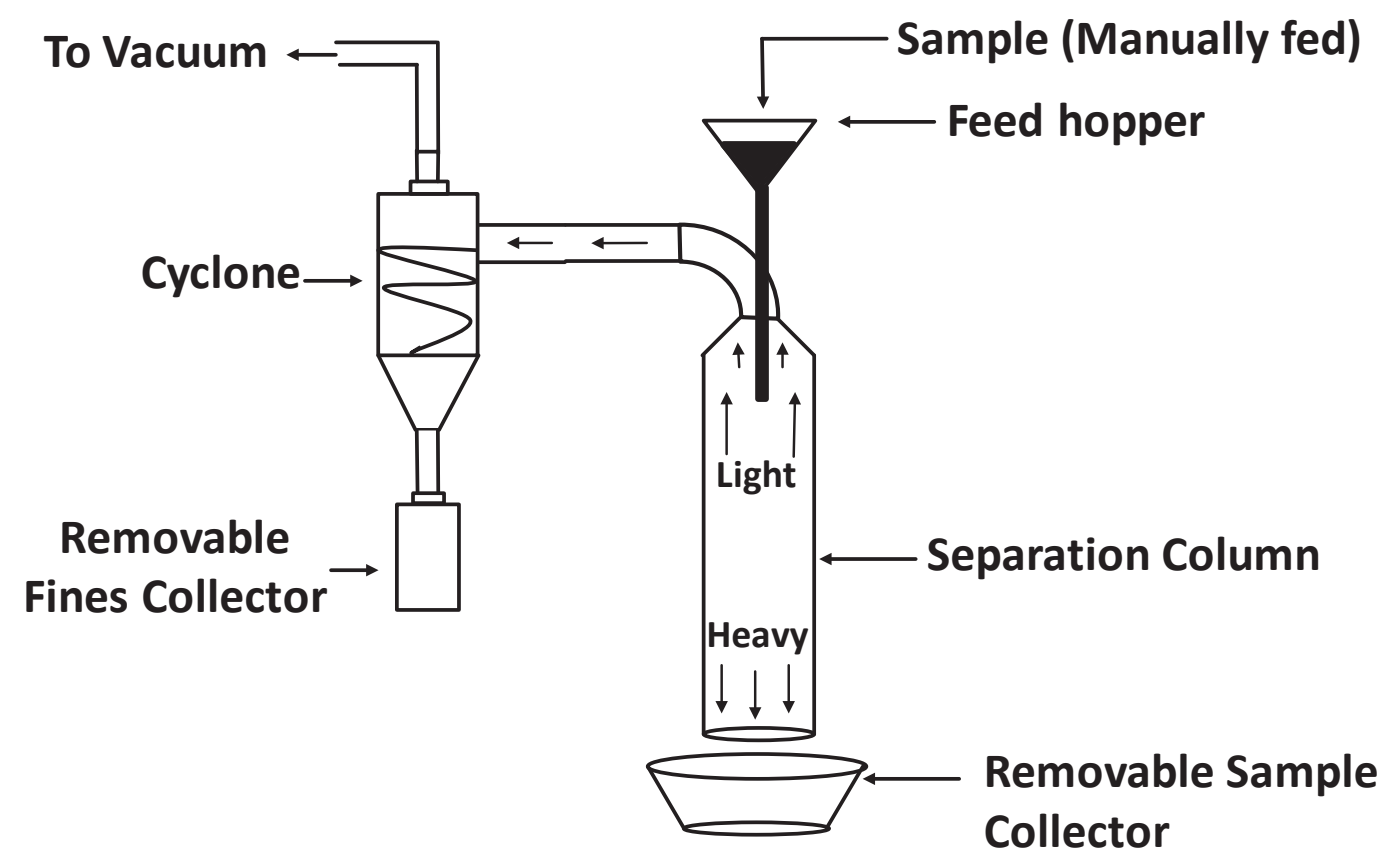

Figure 8: Air classifier -preliminary design

The preliminary air classifier design comprises of a separation column and cyclone as its main constituents (Figure 8). A removable sample collector and fines collector are used to collect the heavy and the light fraction respectively. Counter gravity drag force is induced in the separation column with the help of a vacuum connected to the cyclone overflow.

Air classifier design parameters are as shown in Table 2. (Note: An existing cyclone from the laboratory was used to conduct preliminary studies). The cyclone had the following specifications: body outer diameter: 6 in; body height: 3.75 in; cone height: 10.75 in; inlet outer diameter: $5.5 \mathrm{in}$; height of vortex finder: $1 \mathrm{in}$; diameter of dust outlet: $0.375 \mathrm{in.}$

Table 2: Air classifier (preliminary design) design parameters.

\begin{tabular}{l|c}
\hline \multicolumn{1}{c|}{ Parameter } & Value \\
\hline Length of Separator Column (in) & 36 \\
Diameter of Separator Column (in) & 3 \\
Volume of Fines Collector $\left(\mathrm{cm}^{3}\right)$ & 800 \\
Air flow at Valve fully open (m/s) & 0.56 \\
Type of Vibratory Feeder used & None \\
\hline
\end{tabular}




\subsubsection{Working Principle}

At the beginning of each run air velocity was set to $0.54 \mathrm{~m} / \mathrm{s}$, this was the maximum air velocity that could be attained in the separation column based on the preliminary design. The presence of cyclone in between the separation column and the vacuum causes a high pressure drop and hence lower air velocity in the separation column. Feed was fed manually through the feed hopper. Air velocity in the column produces a drag on the particles suspended in the separation column and separates the mixture in two fractions, light and heavy. The heavy fraction, which is collected at the bottom, is referred to as the preconcentrate here. If drag force dominates gravity force of the particles in motion, they travel upwards and are collected in the cyclone as light fraction; if particle gravity force dominates the induced drag force on particles, they travel downwards and are collected at the bottom as heavy fraction.

\section{Sample preparation:}

Silica samples: Finely ground silica from the bulk sample silica sample was split into subsamples of 45-50 grams each.

Magnetite-silica mixtures: A magnetite silica mixture was prepared by adding 0.5 grams of magnetite powder at the desired size to 45-50 grams of silica.

Blank tungsten samples: The tungsten samples were used alone and not mixture form.

\section{Initial experimental trials:}

- Set I trials: these tests were conducted to observe the separation of silica particles into different size fraction based on particle size

○ Blank silica was run through the air classifier.

○ Air velocity $0.54 \mathrm{~m} / \mathrm{s}$.

○ Manual feeding.

- Set II trials: These tests were conducted to observe change in recovery with varying particle density in a mixture.

- Magnetite-silica mixtures were run through the classifier.

○ Air velocity $0.54 \mathrm{~m} / \mathrm{s}$. 
- Manual feeding.

- Set III trials: These tests were conducted to observe recovery of high density (tungsten) particles.

○ Blank tungsten was run through the classifier.

○ Air velocity $0.54 \mathrm{~m} / \mathrm{s}$.

○ Manual feeding.

Magnetic separation was carried out to recover magnetite from silica.

Note: All the samples were fed to the classifier manually, which may potentially lead to slightly variable feed rates during each trials. 


\subsubsection{Results and Discussions}

Set I results: Blank silica runs

Total material recovered from the top and bottom was $89 \%$, with the heavy fraction accounting to $73 \mathrm{wt} \%$ and the light fraction accounting to $27 \mathrm{wt} \%$. The heavy fraction was observed to be $80 \%$ passing $165 \mu \mathrm{m}$ and the light fraction was observed to be $80 \%$ passing $80 \mu \mathrm{m}$.

\section{Set II results: Magnetite-Silica mixture runs}

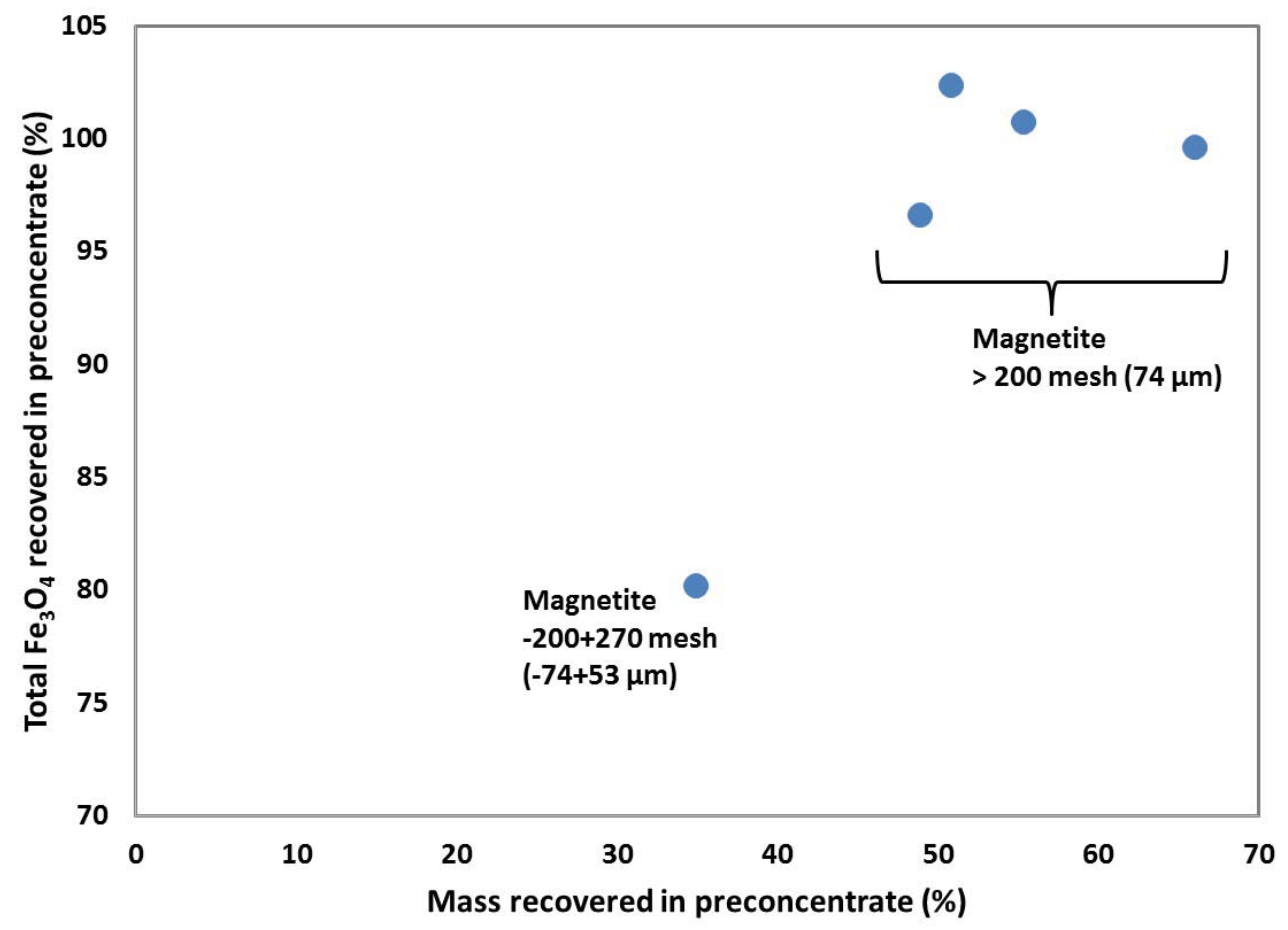

Figure 9: Magnetite-Silica mixture run results

Magnetite silica mixtures containing 45-50 grams of silica and 0.5 grams of magnetite powder of the desired size fraction were fed to the separator and classified at an air velocity of $0.54 \mathrm{~m} / \mathrm{s}$. Results for these trials are shown in Figure 9. It is observed that, for magnetite-silica mixtures the magnetite recovery was consistently high to a particle size of 74 microns. Although the recovery fell significantly as particles size decreased below 74 microns, the results are very promising as tungsten/ gold have a much higher density and should be recovered into the preconcentrate much easier. The only problem was the inconsistency in the mass recovery. As the feed stream fell into the classifier tube, it 
bellowed outwards and some material clung to the walls and some static was noticed in the system after the testing. Problem in mass recovery could easily be corrected by improving airflow and designing a more appropriate air cyclone.

\section{Set III results: Blank tungsten runs}

It was observed that blank tungsten runs through the classifier gave a recovery of $99 \%$ in the heavy fraction and $1 \%$ in the light fraction, suggesting that high density particles can be recovered more efficiently as compared to low density particles due to higher settling velocities. 


\section{Comparison between Preliminary Air Jig and Air Classifier Designs}

Experiments were conducted on the air jig and air classifier. Results from both the designs were compared in terms of mineral recovery, weight of analytical samples generated and feasibility of application to gold samples. During experiments conducted on the air jig with tungsten-silica mixtures, it was observed that tungsten recovery was inconsistent, varying from $67.87 \%$ to $89.25 \%$ at the same set of parameters, frequency combination of 45/60 Hz for a time interval of 2 minutes, for runs 6 to 9 (Table 1).

The air jig could concentrate the bulk sub-samples (tungsten-silica mixtures) down to 120-130 grams consistently due to fixed size of the sample holder, but analytical gold samples were required to weigh between 10-30 grams as specified by Newmont Mining. Air jigging could have been a possible option for gold sampling if the tungsten recovery was consistent. Although the concentrate produced was less than 30 grams, this could have been easily achieved with a redesigned sample holder.

With the air classifier it was observed that runs with magnetite-silica mixtures showed good consistency in magnetite recovery, achieving approximately $99 \%$ recovery for magnetite size greater than 74 micron. Magnetite recovery dropped to $60 \%$ at feed size lower than 74 microns (Figure 8), however the "Nugget Effect" should not be a problem below this particle size. The concentrate weights collected at the bottom were in the range of 20-25 grams. Blank tungsten results showed improved material recovery suggesting that an increase in particle density will have a significant effect on separation.

In the preliminary air classifier, the cyclone was observed to have a high pressure drop, allowing an air velocity of only $0.54 \mathrm{~m} / \mathrm{s}$ in the separation column. This problem can be addressed by re-designing a cyclone such that a lower pressure drop and higher air velocity is achievable in the separation column. Higher air velocity will decrease the preconcentrate sample size. 
The air classifier could be modified in such a way as to control the weight collected at the bottom and to ensure maximum recovery, hence further modifications are done to the air classifier preliminary design as described in the next section. 


\section{Final Design - Air Classifier}

Based on the results from air classifier preliminary design, a final design was proposed.

The preliminary air classifier deign was modified in the following ways:

- Control valve: a control valve was installed on line between the cyclone and the separation column. The control valve helps in controlling the air velocity in the separation column, which in turn helps in achieving control over the drag force on particles, controlling separation.

- Vibratory feeder: A vibratory feeder was installed over the feed hopper. The vibratory feeder helps in achieving control over the feed rate with which particles fall into the separation column.

- Air-cyclone: a new cyclone based on Stairmand/Swift cyclone design (Majumdar 2007) was built (Figure 10). Standard parts were ordered and cyclone was assembled with the dimensions given in Table 3:

Table 3: Cyclone design parameters

\begin{tabular}{|c|c|c|c|}
\hline & \multicolumn{3}{|c|}{ Cyclone Type } \\
\hline & \multicolumn{3}{|c|}{ High Efficiency } \\
\hline & Stairmand & Swift & $\begin{array}{c}\text { Laboratory } \\
\text { designed }\end{array}$ \\
\hline Body Diameter (D/D) & 1 & 1 & 1 \\
\hline Height of Inlet (H/D) & 0.5 & 0.44 & 0.33 \\
\hline Width of Inlet (W/D) & 0.2 & 0.21 & 0.33 \\
\hline Diameter of Gas Exit (De/D) & 0.5 & 0.4 & 0.33 \\
\hline Length of Vortex Finder (S/D) & 0.5 & 0.5 & 0.66 \\
\hline Length of Body (Lb/D) & 1.5 & 1.4 & 1.33 \\
\hline Length of Cone (Lc/D) & 2.5 & 2.5 & 3.33 \\
\hline Diameter of Dust Outlet (Dd/D) & 0.375 & 0.4 & 0.292 \\
\hline
\end{tabular}



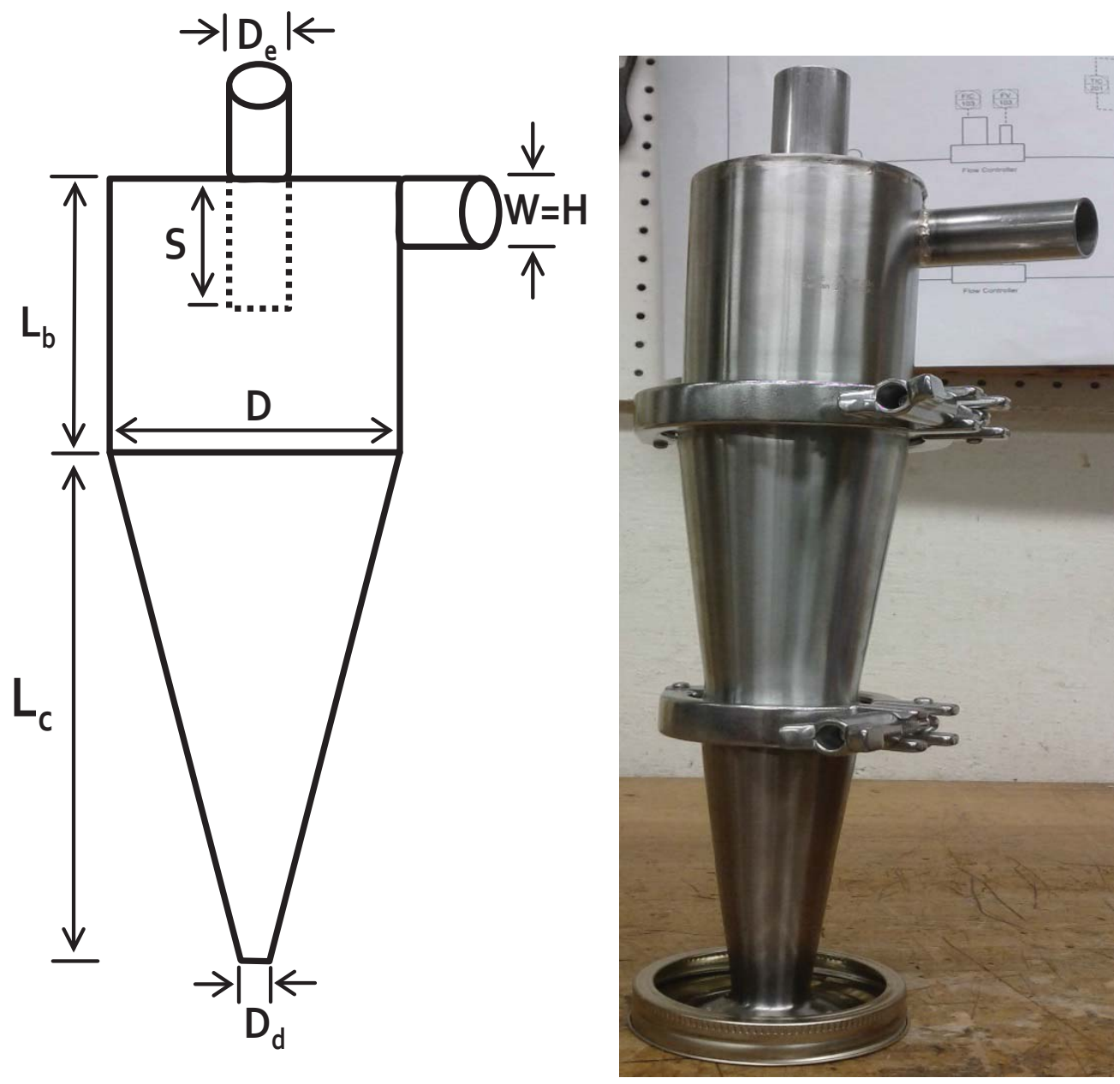

Figure 10: Cyclone design and cyclone made at Michigan Technological University. 


\subsection{Materials}

Synthetic ore was prepared by mixing silica and tungsten powder to produce a $0.25 \%$ w/w tungsten mixture. This was intended to mimic the composition of gold ore. A few additional experiments were run with iron powder to determine density effects on separation.

Silica: Ottawa sand was sized to achieve a size distribution of $80 \%$ passing 150 mesh.

Silica density was measured to be $2.64 \mathrm{~g} / \mathrm{cm}^{3}$.

Tungsten powder: Tungsten powder was procured from Buffalo Tungsten Inc. and was used as received. Tungsten powder had a size distribution of 75\%, +200 mesh and 25\%, -200 mesh and density was measured to be $19.17 \mathrm{~g} / \mathrm{cm}^{3}$ (close to gold: $19.25 \mathrm{~g} / \mathrm{cm}^{3}$ ). A few tests were conducted using only the +200 mesh powder to study effects of particle density at a specific size range.

Iron Powder: Iron powder was procured from Chemical Store, screened and the -100 +200 mesh fraction was retained for experimentation. The iron powder density was determined to be $6.73 \mathrm{~g} / \mathrm{cm}^{3}$.

Powder density was determined using specific gravity bottles. 


\subsection{Experimental Setup:}

The air classifier designed and built for the experiments is shown in the Figure 4.

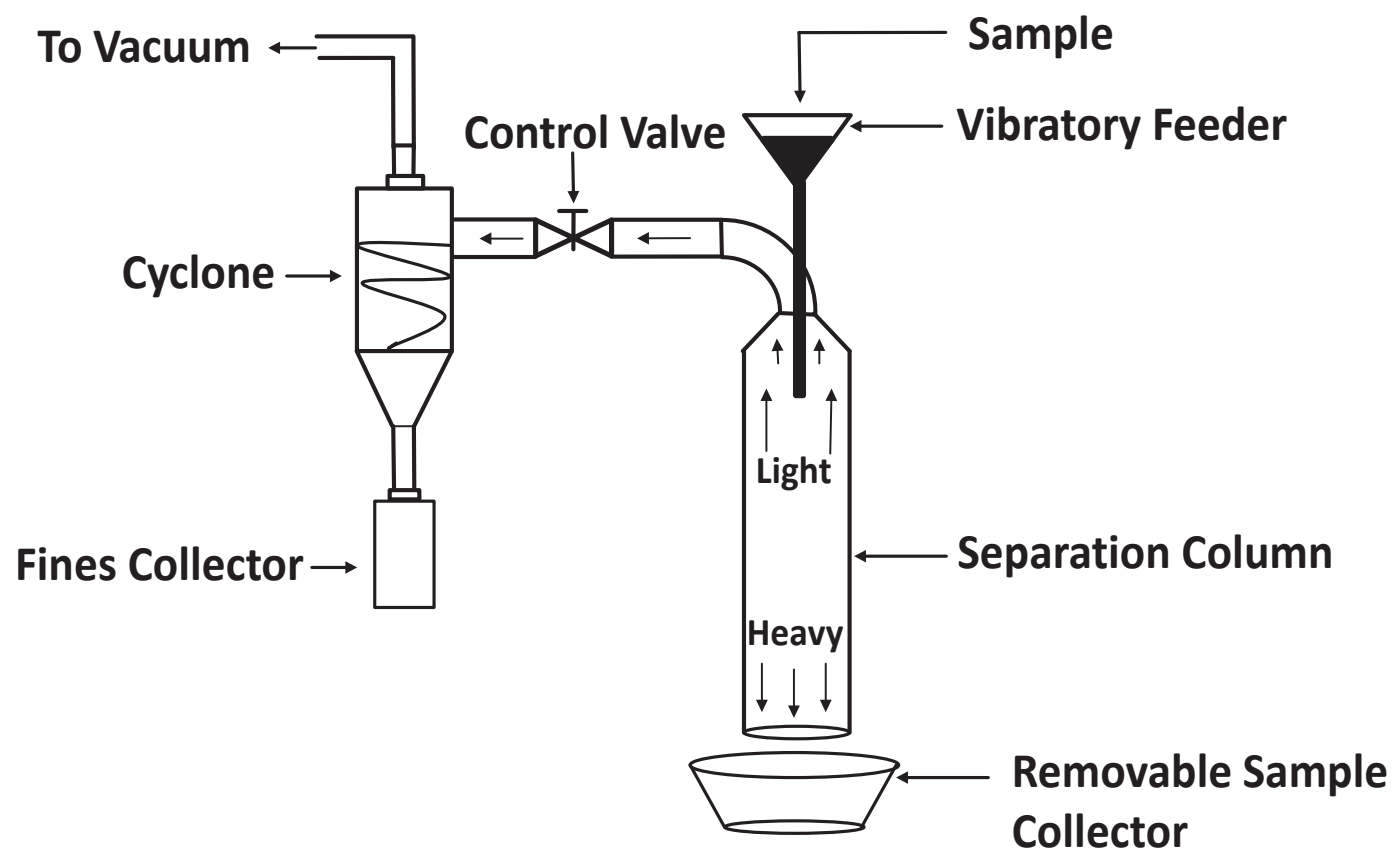

Figure 11: Air Classifier schematic

The air classifier has the following parts:

- Separation column: particles suspended under the influence of drag force are separated in the separation column based on their terminal settling velocities.

- Control valve: controls the air velocity induced in the column.

- Vibratory feeder: controls the feed rate at which particles enter the separation column.

- Cyclone: assists the collection of separation column overheads (fines) to the fines collector.

- Fines collector: collects fines from the cyclone.

- Removable sample collector: collects the heavy fraction.

Laboratory set-up on the next page in Figure 12 


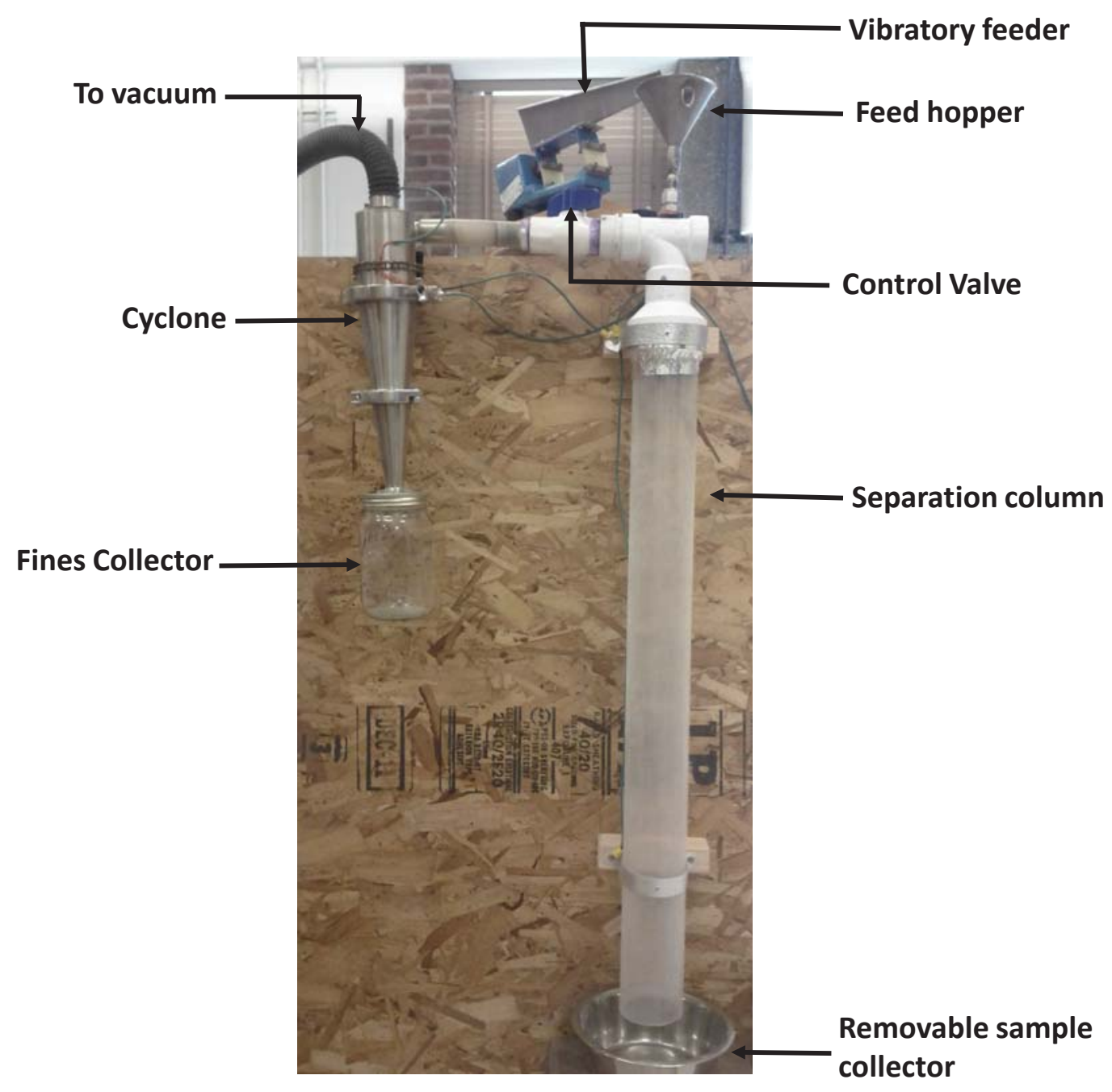

Figure 12: Air classifier laboratory set-up

\section{Ease of Cleaning}

The air classifier was cleaned after each run by blowing compressed air through the entire system. This helped to blow out the fine particles accumulated in joints and bends at the connections.

\subsection{Working Principle:}

At the beginning of each run, the control valve was adjusted and air velocity in the separation column was set. Similarly, the feed rate was set by adjusting the vibratory feeder. Feed is sent in through the vibratory feeder. While feed mixture moves down the separation column, induced drag force due to air velocity acts on the feed particles and 
separates the mixture into two fractions, light and heavy. If particles have terminal settling velocity greater than the separator air velocity, they will be collected at the bottom as the heavy fraction. Conversely, particles having terminal settling velocity lower than the separator air velocity, they will be swept out of the separation column as the light fraction. Air velocities were adjusted to $0.72,0.85$ and $1 \mathrm{~m} / \mathrm{s}$ and feed rates ranging from 93 to 306 $\mathrm{g} / \mathrm{min}$ were tested. Reynolds number for air velocities $0.72,0.85$ and $1 \mathrm{~m} / \mathrm{s}$ were calculated to be 4000,4700 and 5500 respectively, implying that the air flow in the separation column was turbulent.

\section{Estimating tungsten recovery:}

Tungsten recovery was estimated by manually hand panning the bottom fraction of the separation column collected in the removable sample collector (Figure10). In order to determine the precision and accuracy of our panning technique tungsten-silica mixtures of representative sample sizes and of known concentration were hand panned. Tungsten recovery averaged $99.7 \%$ for 3 runs from mixtures containing 0.5 grams tungsten in 30 grams $\mathrm{SiO}_{2}$, with a standard deviation of 1.042 . 


\subsection{Results and Discussions}

The feasibility of a vertical-duct air classifier to pre-concentrate metallic particles from analytical samples was investigated by varying air velocity in the classifier and sample feed rate. Design goals for the air classifier were to:

a) Produce a concentrate sample with a mass of 10-30 grams containing all metallic particles in the analytical sample;

b) Collect in excess of $95 \%$ of the material fed to the system.

\subsubsection{Percent tungsten recovered in the bottom fraction}

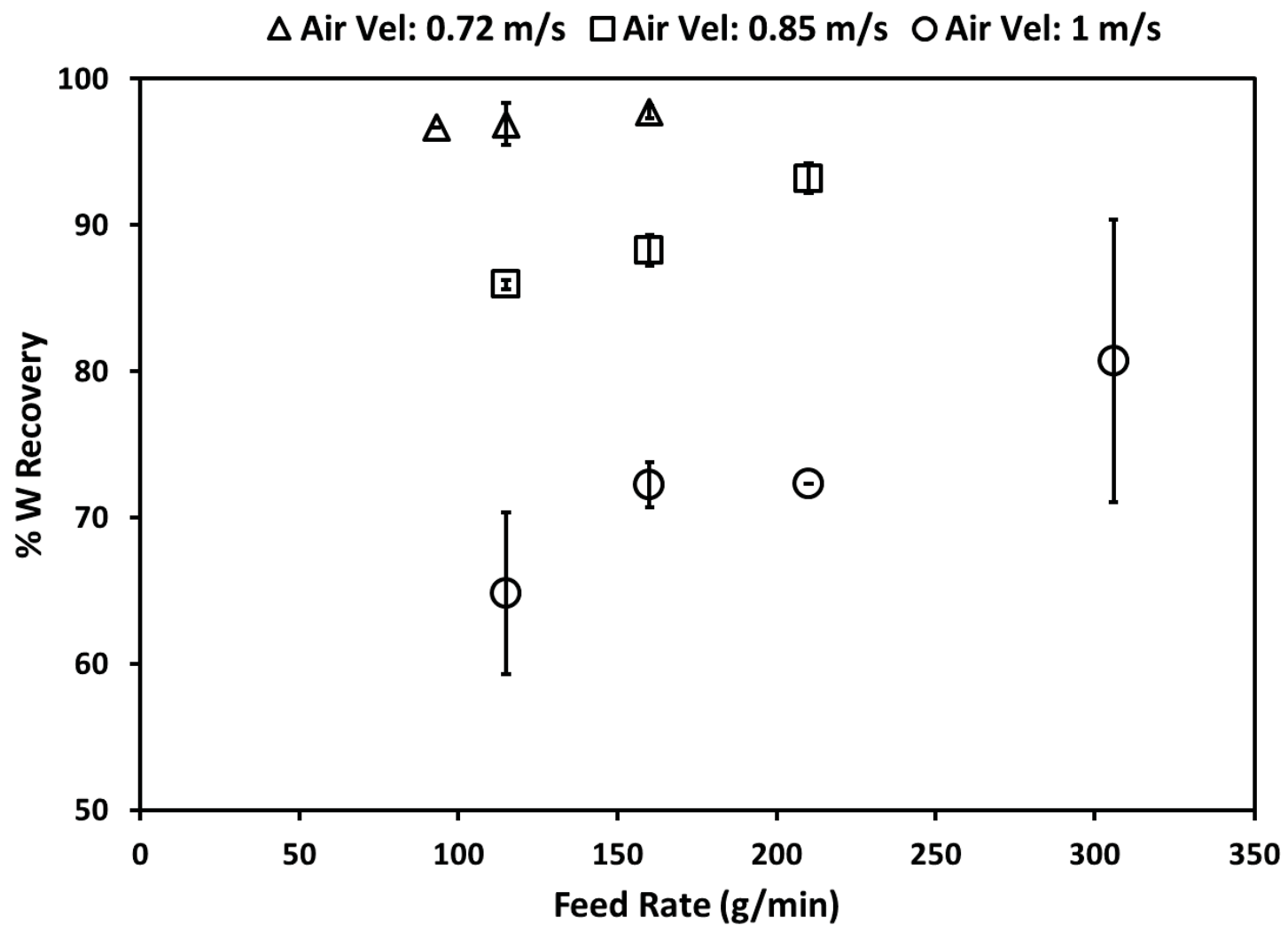

Figure 13: Tungsten recovery into the fire assay concentrate

Sample collected at the bottom were hand panned and analyzed for tungsten recovery. Our aim was to investigate effects of air velocity and feed rate in order to achieve maximum tungsten recovery. Tungsten recovery results are as shown in Figure 13. 
It was observed that for a given air velocity, as feed rate increases the tungsten recovery increases. This can be explained based on the interaction between the entire incoming feed and the upward flowing air. Higher feed rates may have forced the feed stream to "short-circuit" the separation and fall directly to the bottom. This is corroborated by Figure 14, which shows significant increase in bottoms material recovery at higher feed rate, and

, which shows higher tungsten recovery at higher preconcentrate sample sizes.

For a given feed rate, as the air velocity increases, lower tungsten recoveries were achieved. This may be due to the tungsten size distribution, of which about $25 \%$ of the material was finer than 200 mesh. At higher air velocities, more and more fine material would be swept out of the separation column. Additional tests conducted without the 200 mesh fraction had significantly higher tungsten recoveries (Figure 18). 


\subsubsection{Weight collected at the bottom.}

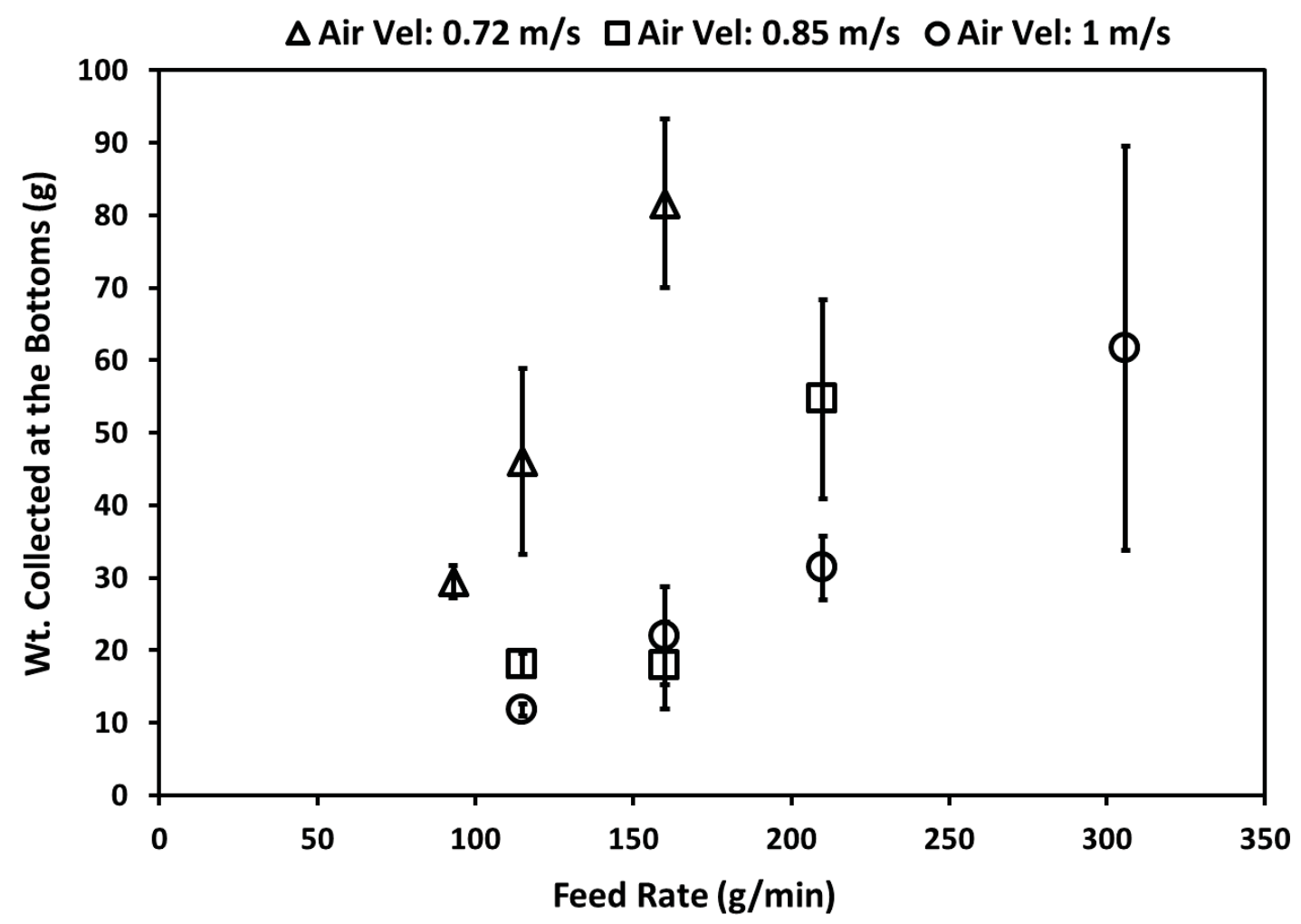

Figure 14: Weight collected at the bottom of the air classifier (direct fire assay sample)

Primary importance was given to controlling the weight collected at the bottom of the separator column (heavy fraction), because our project aimed to generate samples which can be fire assayed directly to measure the metal content. The criteria for fire assay requires samples to be 15-30 grams in mass; hence runs at higher feed rate for air velocity 0.72 and $0.85 \mathrm{~m} / \mathrm{s}$ are not carried out (Figure 14).

It was visually observed that as feed rate increases for a given air velocity, particles enter the separator tube more like a closely packed rope, shielding each other from the upflowing air.

Consequently as feed rate increased, the weight collected at the bottom of the separation column increased. 


\subsubsection{Relationship between total tungsten recovered in the}

preconcentrate (\%) and preconcentrate sample size

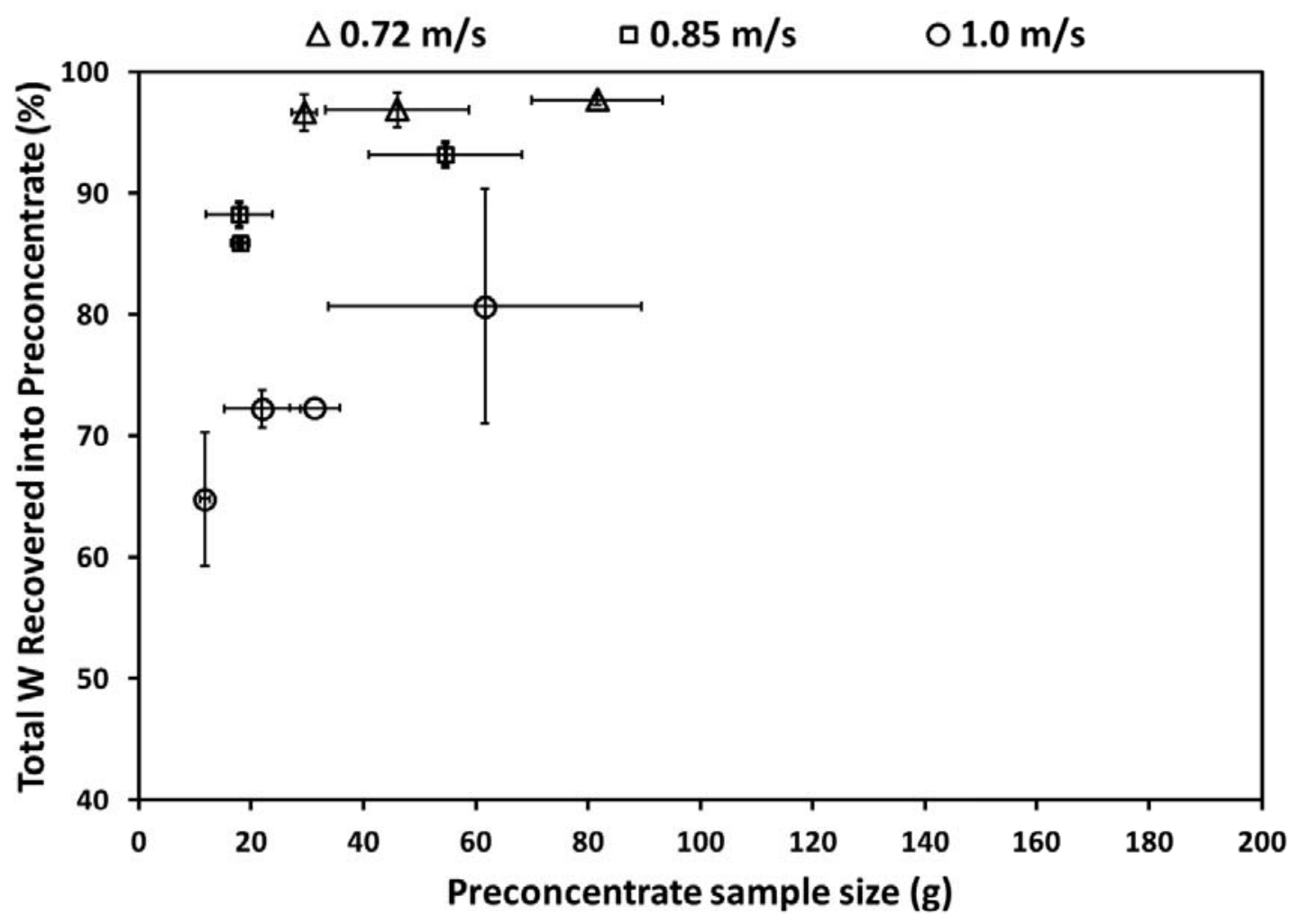

Figure 15: Tungsten recovered vs preconcentrate sample size

Tungsten recovered in the preconcentrate increases with the weight collected at the bottom. As air velocity increases, less mass is collected into the preconcentrate sample as expected. However at the higher feed rates, more of the fine tungsten and fine silica (which would tend to be swept out of the separation column at higher air velocity) is forced to the bottom. Hence, tungsten recovery increases.

Optimum tungsten recoveries greater than $97.7 \%$ were obtained at an air velocity of 0.72 $\mathrm{m} / \mathrm{s}$ and feed rate $93 \mathrm{~g} / \mathrm{min}$. Similar recoveries were observed at air velocities of $0.85 \mathrm{~m} / \mathrm{s}$, for tungsten +74 microns, Figure 18 . We were able to consistently produce a preconcentrate sample of the desired size containing essentially all of the metallic nuggets. 


\subsubsection{Total material recovery from the system}

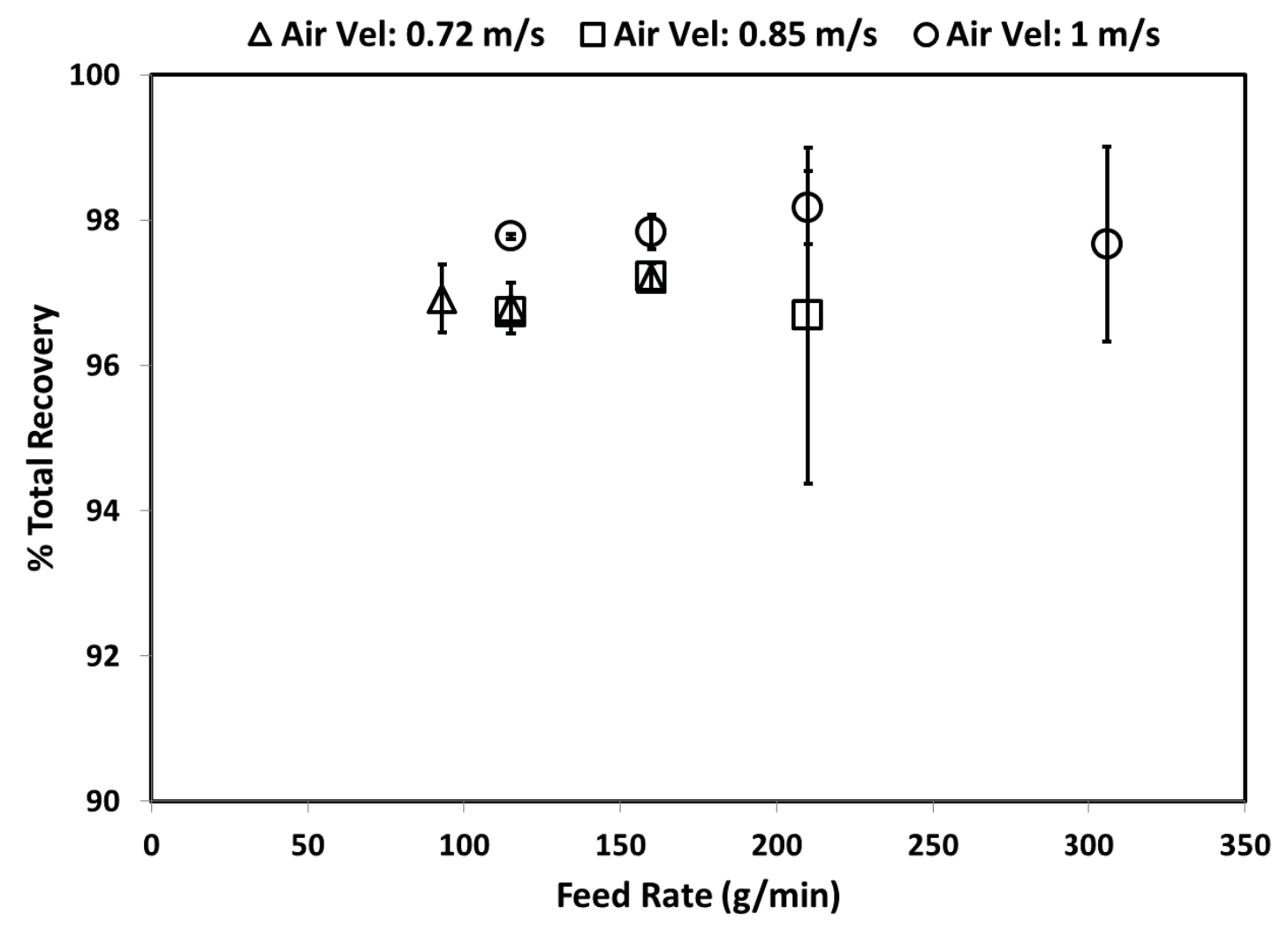

Figure 16: Total material recovery (fines fraction plus heavy fraction)

When processing valuable minerals like gold, it was important to ensure minimum material loss into the vacuum. Estimating the total mineral recovery helps in analyzing the air classifier performance. The $\%$ total material recovery is given by:

$$
\text { Percent total material recovery }=\frac{\left(W_{P}+W_{C}\right) * 100}{W_{A}}
$$

\section{Equation 5}

Where,

$W_{P}=$ Weight of the preconcentrate collected at the bottom of the air classifier

$W_{C}=$ Weight of the overflow collected by the air cyclone

$W_{A}=$ Weight of sample fed to the air classifier 
It was observed that changes in feed rate for a given air velocity do not have a significant effect on total material recovery, but at higher feed rates, there is more inconsistency in recovery. This may be because, at higher feed more material enters the cyclone and hence there are more chances that it might bypass the cyclone.

It was also observed that increases in air velocity for a given feed rate increases the cyclone inlet velocity, increasing the centrifugal force on incoming particles and ensuring better entrapment of fines. 


\subsubsection{Cyclone Efficiency}

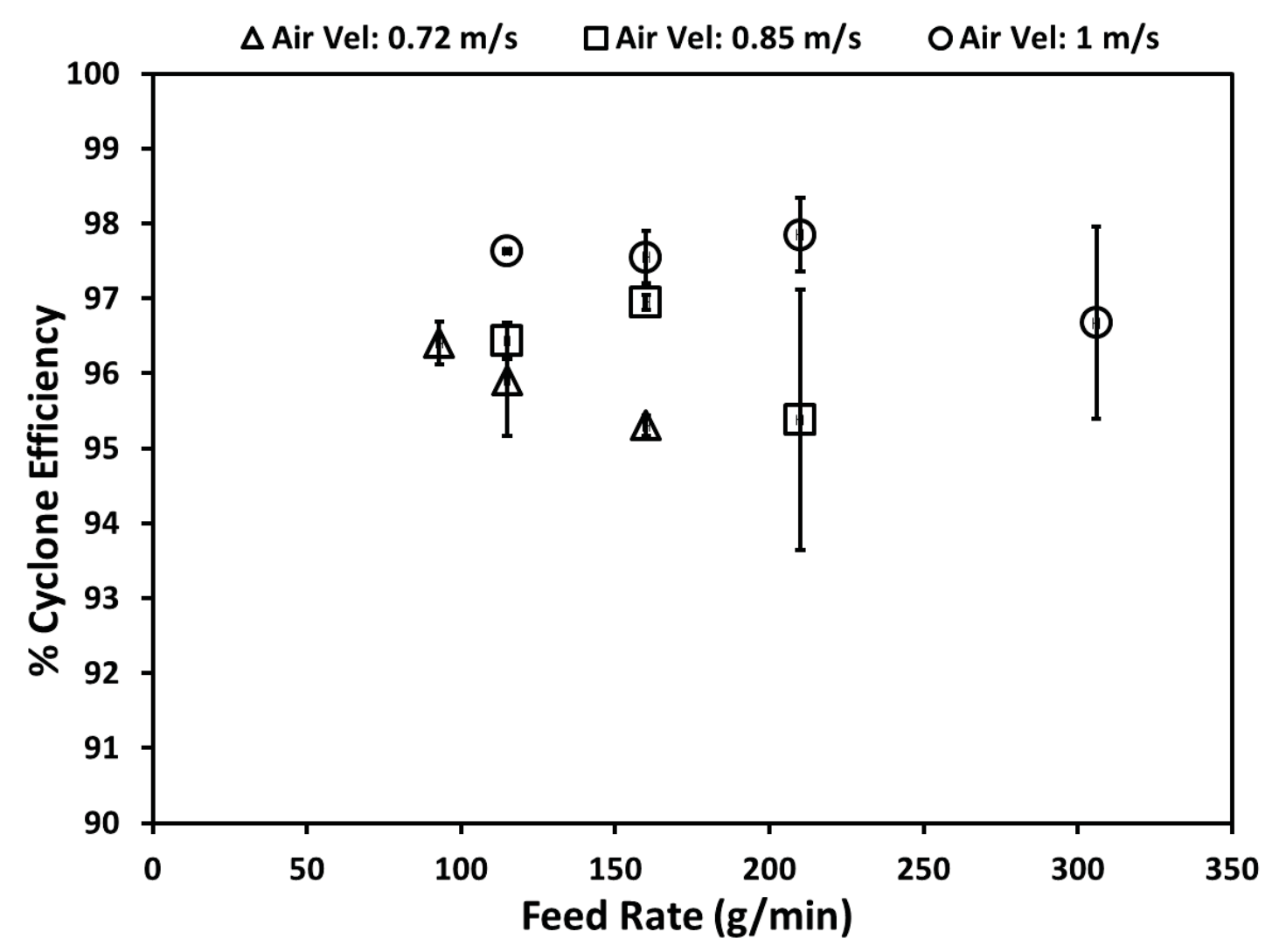

Figure 17: Cyclone efficiency

The air classifier separated material into two fractions, light and heavy. The heavy fraction was collected at the bottom, and the light fraction was collected by the cyclone as fines from the separator tube. Our aim was to design a cyclone with maximum efficiency in order to ensure that the fine tungsten particles are recovered during rapid testing. Cyclone efficiency was calculated based on Equation 6:

$$
\text { Cyclone efficiency }=\frac{(\text { Wt. collected by the cyclone }) * 100}{(\text { Wt. fed }- \text { Wt. of Heavy Fraction })}
$$

Equation 6

Results are as shown in Figure 17. It was observed that change in feed rate at a given air velocity does not have a significant effect on the cyclone efficiency; the efficiency fluctuates within a maximum average range of $1.5 \%$. Also as air velocity increases for a given feed rate, cyclone efficiency was observed to increase. This could be explained 
based on the fact that higher inlet velocity at the cyclone helps in strong vortex formation due to increase in centrifugal force in the cyclone body, facilitating the entrapment of ultra-fines. But under all conditions, the cyclone achieved efficiency greater than $95 \%$, implying that the cyclone design worked well enough for rapid tests.

While fines were efficiently collected, a few samples of ultra-fines that bypassed the cyclone were analyzed in SRA Microtrac, and it was seen that particles were below 20 microns. 


\subsubsection{Tungsten and Iron recovery comparison}

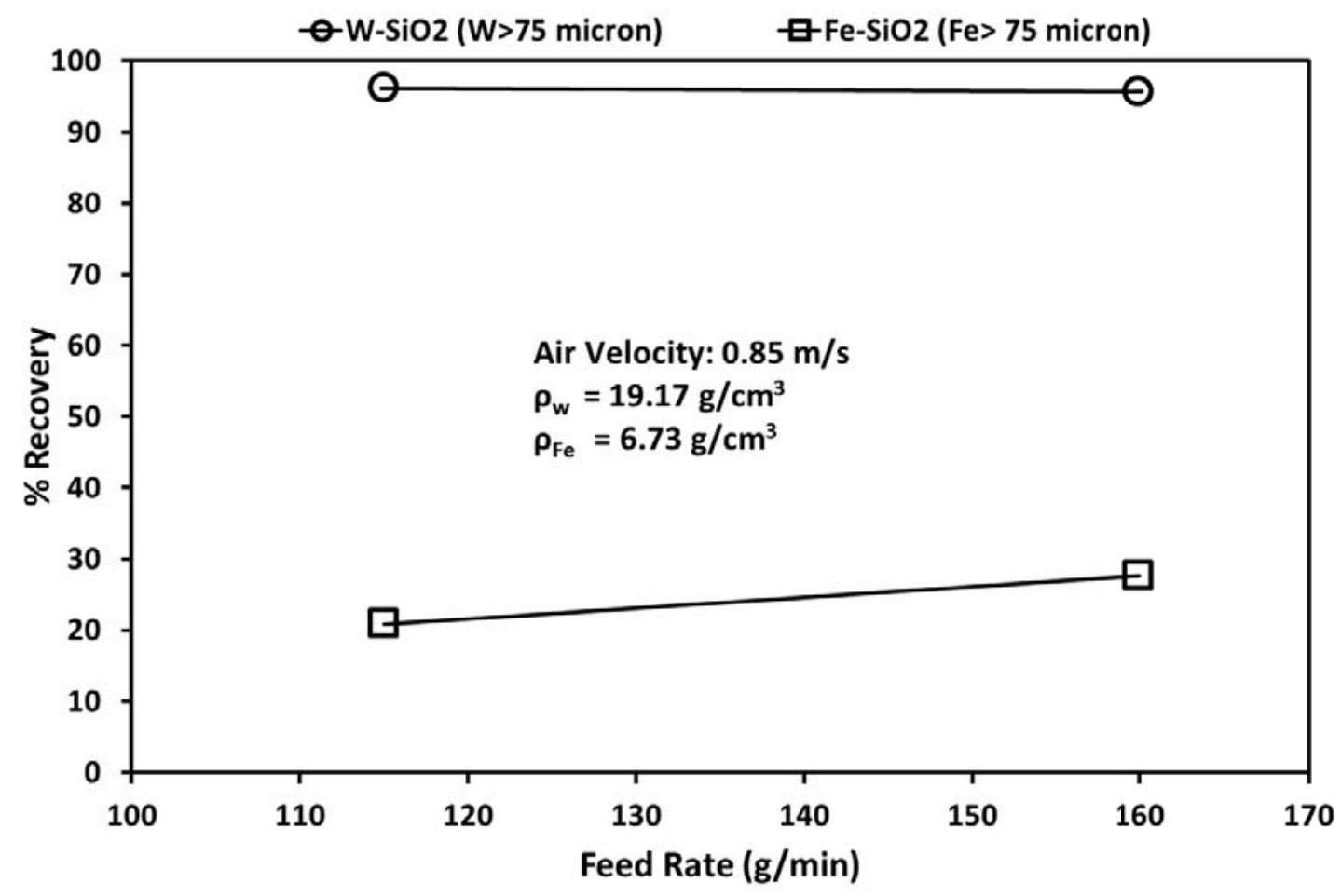

Figure 18: Mineral recovery comparison with change in density. Tungsten and iron particles sizes were both above 75 microns

Density effects on mineral recoveries were investigated by running mixtures of TungstenSilica and Iron-Silica through the separation column. Figure 18 shows that tungsten was separated much more efficiently than iron due to tungsten's high density. 


\section{Conclusions}

In experiments using tungsten as an analog for gold nuggets, it was found that an air classifier was easier to construct and gave better performance than an air-jig. Air velocity $0.72 \mathrm{~m} / \mathrm{s}$ and feed rate $93 \mathrm{~g} / \mathrm{min}$ resulted in optimal preconcentration of the bulk samples to heavy fractions weighing 10-30 grams with $96.68 \%$ tungsten recovery, suggesting that if gold nuggets are present in the ore, they could potentially be collected in the bottom fraction and directly fire assayed. This coheres with our project objective.

Tungsten and iron recovery comparisons suggest that density affects the aerodynamic behavior of particles under the influence of drag force, for an air velocity of $0.85 \mathrm{~m} / \mathrm{s}$ and feed rate $160 \mathrm{~g} / \mathrm{min}$, tungsten and iron recoveries were $95.67 \%$ and $27.63 \%$ respectively. High cyclone efficiency (>95.3\%) and consistency ensures a reliable cyclone design for entrapment of fines and minimal dust losses. Preliminary investigations suggest that preconcentration of gold samples is feasible using the laboratory designed air classifier. Future work is planned to be conducted using analytical gold samples. 


\section{Future Work}

For future we propose to test the air-classifier on actual gold samples for fire assay. The results will be compared to a screening procedure similar to current analytical practice. Proposed tasks are as follows:

- More samples weighing 200 grams will be studied to investigate possible effects of mineralogy on separation. Particle size, density, and shape are expected to change between the different ores and may affect separation performance. Size distribution and density will be measured for each sample.

- Samples will be processed through the air separator. Size distribution and density will be used to predict an appropriate air velocity for separation. The air separator will then be tested at 2 velocities near the predicted value and 3 feed rates, with 3 replicates at each test condition. These tests will be repeated for each ore type to understand separator performance on relevant gold samples.

- Each lot will also be analyzed following Newmont's (funding agency) current analytical screening procedure (as described by Newmont), or a mutually acceptable alternative.

- The air separator will be evaluated against the screening procedure: 1) did it reduce the nugget effect? 2) is it faster to operate and less labor-intensive? 3) is it easier to operate and keep clean? 


\section{References}

- Baron, P.A., Kulkarni, P. and Klaus, W. (2001). Aerosol Measurement - Principles, Techniques, and Applications (2nd Edition) Aerosol Measurement - Principles, Techniques, and Applications (2nd Edition), John Wiley and Sons.

- Carrasco, P.C. (2010). "NUgget effect, artificial or natural? ." The Journal of The Southern African Institute of Mining and Metallurgy 110.

- EPA (2011). Vocabulary Catalog List Detail - Integrated Risk Information System (IRIS) Glossary. Environmental Protection Agency, http://ofmpub.epa.gov/sor internet/registry/termreg/searchandretrieve/glossariesan dkeywordlists/search.do?details=\&glossaryName=IRIS\%20Glossary.

- Everett, J. and Peirce, J. (1990). "Effect of Feed Rate and Classifier Height on Air Clasification." Journal of Environmental Engineering(109): 735-745.

- Gupta, A. and Yang, D.S. (2006). Mineral Processing Design and Operations: An Introduction. Amsterdam, Elsevier

- Krenzler, L.M. (1999). Gold pan with delivery cups. United States of America.

- Majumdar, A.S. (2007). Handbook of Industrial Drying, Taylor and Francis Group.

- Muscolino, J. (2010). "Mechanical Centrifuge Air classifiers." Chemical Engineering: 4850 .

- $\quad$ Oder, R.R. and Weinstein, R.S. (2008). "Air jig for separation of minerals from coal." US Patent US 7367456 B2.

- Vickery, J.D. (1991). Method and apparatus for air separation of material. United States.

- Wills, B.A. (1985). Mineral Processing Technology. Cornwall, England., Pergamon Press.

- Wilson, L. and Huang, T.C. (1979). "The influence of shape on the atmospheric settling velocity of volcanic ash particles." Earth and Planetary Science Letters 44(2): 314-325. 
- Zelenyuka, A., Caia, Y., Chieffob, L. and Imrec , D. (2005). "High Precision Density Measurements of Single Particles: The Density of Metastable Phases." Aerosol Science and Technology 39(10). 